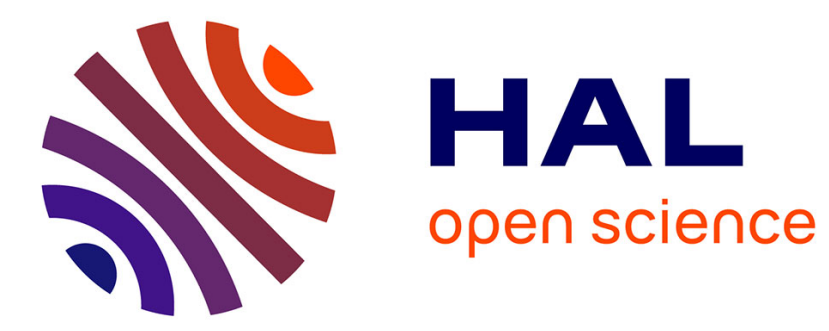

\title{
The determination of public tuition fees in a mixed education system: A majority voting model
}

\author{
Hejer Lasram, Didier Laussel
}

\section{To cite this version:}

Hejer Lasram, Didier Laussel. The determination of public tuition fees in a mixed education system: A majority voting model. Journal of Public Economic Theory, 2019, 21 (6), pp.1056-1073. 10.1111/jpet.12317 . hal-01992143

\section{HAL Id: hal-01992143 \\ https://hal-amu.archives-ouvertes.fr/hal-01992143}

Submitted on 12 Feb 2020

HAL is a multi-disciplinary open access archive for the deposit and dissemination of scientific research documents, whether they are published or not. The documents may come from teaching and research institutions in France or abroad, or from public or private research centers.
L'archive ouverte pluridisciplinaire HAL, est destinée au dépôt et à la diffusion de documents scientifiques de niveau recherche, publiés ou non, émanant des établissements d'enseignement et de recherche français ou étrangers, des laboratoires publics ou privés. 


\title{
The determination of Public Tuition Fees in a Mixed Education System: A Majority Voting Model
}

\author{
Hejer Lasram* $\quad$ Didier Laussel ${ }^{\dagger}$
}

January 19, 2017

\begin{abstract}
We analyze the issue of majority voting equilibrium for the determination of public tuition fees. We consider a model with mixed education system where public and private universities coexist and compete in tuition fees. Since there is a private alternative, preferences for education are not single-peaked and no single-crossing condition holds. An equilibrium is shown to exist which is one of three types: high tuition fee (the "ends" are a majority), low tuition fee (the "middle" is a majority) or mixed (votes tie). the cost structure determines which equilibrium obtains. The equilibrium tuition is either greater (majority at the ends) or smaller (majority at the middle) than the optimal one.
\end{abstract}

\section{Introduction}

The determination of public universities' tuition fees has recently attracted a lot of attention following the important evolutions observed in some countries. Martin (2002), on the basis of 1995-2002 data, already noted an increase in tuition $\operatorname{costs}^{1}$ much faster than inflation or family income. The same observation was more recently made on the period 2003-2013 by Desrochers and Hulburt (2016) for US colleges. The most striking recent case of a dramatic increase of the tuition fees is the United Kingdom where tuition fees were first introduced in September 1998 under the (New) Labour Government, with students being required to pay up to $£ 1,000$ a year for tuition. This amount was raised to a maximum of $£ 3,000$ in 2004 . and to $£ 9,000$ a year from 2012 , with 64 universities charging the maximum of $£ 9,000$ and the remaining 56 charging at

\footnotetext{
${ }^{*}$ U.R. MASE-ESSAI, Université de Carthage; Aix-Marseille Univ. (Aix-Marseille School of Economics), CNRS, EHESS and Centrale Marseille, 18 rue Rabaa el Adaouia Manzah 7 Ariana 2037, tel: +216 23170 196, E-mail: hejer.lasram@gmail.com

${ }^{\dagger}$ Aix-Marseille Univ. (Aix-Marseille School of Economics), CNRS, EHESS and Centrale Marseille. E-mail: didier.laussel@outlook.fr

${ }^{1}$ for public and private unversities.
} 
least $£ 6,000^{2}$. Austria introduced in 2000 a 363 euros per semester tuition fee, following 30 years without tuition. Another example of a hike of tuition fees decided by the government is Quebec, where the 2013 increase though modest encountered a strong opposition.

Martin (2002) attributed the increase in tuition fees to "the increasing time given to professors for scholarship and other activities", that is to "increases in noninstructional staff" 3 . This factor however cannot account for the wide cross-country differences in tuition fees which are currently recorded. Marcucci and Johnstone (2007) for instance distinguish between countries without public tuition fees (such as Brazil, Denmark, Germany, Norway, Sweden among others), countries with up-front tuition fees (including Belgium, Canada, Chile, Italy, Portugal, United States) and countries with deferred tuition fees (Australia, England, Wales..). According to Marcucci and Johnstone ((2007), Table 1, page 29), medium public tuition fees for first degrees ranged from 0 (Hungary, 2001) to $9000 \$$ (USA, 2004/2005). Given the extent of these differences in tuition fees, which largely exceed possible differences in costs for similar countries, it is natural to look at political factors. More importantly, a pure cost approach cannot account for the dramatic increases in public tuition fees observed in some countries, as reported above, compared to their stability in many others. This is another reason for looking at political factors. More specifically, we will show here that, in some range of parameter values, a small variation of costs may lead, through a "tilting of majority" effect to an important increase in public tuition fees, when it increases the attractiveness of the private university in such a way as to lead to a majority reversal.

In order to understand the political factors contributing to the determination of tuition fees, we consider a model with a mixed education system where there is a private university which offers higher quality than its public competitor, incurring thus a higher unit cost per trained student. In this vertical differentiation framework, we assume that the agents are differentiated with respect to the individual benefits which they are able to derive from education. The two universities determine simultaneously their tuition fees. In the first stage of the game, the public university's tuition fee is fixed by majority voting while that of the private university by profit maximization. In the second stage, the agents choose to train in the public university or in the private one or not to train at all, then the tax per head adjusts in order to balance the State budget.

Related literature A number of papers have analyzed the determination of the public provision of education through majority voting. Using a numerical example calibrated to actual data, Barzel (1973) was the first to raise the issue of non-single-peaked preferences for education in mixed school systems where education is provided by both public and private institutions. He noticed that

\footnotetext{
${ }^{2}$ Notice that, following devolution, tuition fees have been abolished in Scotland.

${ }^{3}$ He also pointed to the "reduced public subsidies for higher education", i.e. a political factor.
} 
while public education is provided uniformly, regardless of households' preferences, "private schools provide an opportunity to obtain the desired quantity" (page 176). In his example, he shows that the richest of the seven income segments opts indeed for private education. Stiglitz (1974) trying to test the Pareto-optimality of the provision of education under various institutional arrangements, considered in his Section 4 mixed public-private school systems and noted (p. 365) that "the absence of single-peaked preferences means that there may not be a majority voting equilibrium" regarding the amount of publicly provided education. Glomm and Ravikumar (1998) pioneered the analysis of endogenous provision of public education when there is a private alternative and proved that a majority voting equilibrium exists, in which the median income voter is pivotal, under conditions on the utility function and the income's distribution which amount to assume that any utility function satisfies a singlecrossing condition ${ }^{4}$. More precisely, this condition implies that the marginal willingness to pay $^{5}$ for a higher level of public education decreases with income. Without private alternative, this "SDI" property (slope declining in income) would entail an inverse relationship between the most preferred level of public provision of education and income. This inverse relationship is even reinforced when a private alternative exists ${ }^{6}$. Epple and Romano (1996a) did call this property "SDI" and globally confirmed Glomm and Ravikumar (1998) results. They generalized them by considering as well the opposite assumption of "SRI" (slope rising in income), under which single crossing fails. They provided only necessary conditions for the existence in that case of a majority voting equilibrium, namely the existence of two groups of equal sizes: a coalition ("the middle") of intermediate income types which would favor a higher provision of public education and a coalition ("the ends") of both lower and higher income types which would prefer a smaller level of public education expenditures, the rich opting for private education.

Another set of papers (Epple and Romano, 1996b; Bearse et al., 2005) focused on private supplements to public education. Contrarily to Epple and Romano (1996b), Bearse et al. (2005) consider in addition a private alternative for education. Other papers as De la Croix and Deopke (2009) enlarged the analysis linking voting on public schooling expenditures to private education and fertility decisions.

In this paper, we depart from the above literature in several important respects. First, we consider here that higher education is an investment good rather than a consumption good: agents who choose to train consider the additional income they will earn once educated. Second, we suppose that the private university behaves strategically rather than assuming a perfectly com-

\footnotetext{
${ }^{4}$ This was pointed out by Epple and Romano (1996a). The use of single-crossing conditions in voting models go back to Roberts (1977).

5 through a proportional tax rate increase.

${ }^{6}$ An illuminating proof is in Epple and Romano (1996a, p.308). The intuitive argument is (i) SDI entails that agents' marginal willingness to pay for public education decreases with income, absent any private alternative and (ii) the possibility of switching to private education reduces even more richer people benefits from public provision.
} 
petitive education supply. Finally, rather than studying the determination of the public provision of education, we focus on the determination, through majority voting, of the tuition fees at the public universities, assuming that training is not necessarily given there for free. In a standard vertical differentiation model, we consider agents which differ in the individual benefits which they are able to derive from education and we assume that the quality of education at the private university is exogenously higher than at the public one. Depending on the private and public tuition fee levels, there are three groups of agents ranked in order of increasing return on education: those who don't train, those who train at the public university and those who train at the private university. Going to the private university is here the way to get a higher quality education leading to better paid jobs. Given that the tax level is adjusted so as to balance the public budget, the first and the third groups favor high tuition fees while the second one prefers low tuition fees: this is the "ends against the middle" feature put forward by Epple and Romano (1996a).

Main results. In this model, (i) agents' preferences are not generally singlepeaked and (ii) no single crossing condition holds. These are features typically associated with a "middle against the ends" framework. Nevertheless, whereas Epple and Romano (1996a) only provided necessary existence conditions, we are able to prove here, for any value of the private university tuition fee, the existence of a majority voting equilibrium. Endogenizing the determination of the private tuition fee, we then prove the existence of three different types of equilibria: (i) an equilibrium in which the "ends" are a strict majority and select a high public tuition fee, higher than the cost per student, (ii) an equilibrium where the "middle" is a strict majority and selects a low public tuition fee, in many cases smaller than the cost per student, and (iii) a "mixed equilibrium" in which votes tie and the public university randomizes between the high and the low public tuition fees. The cost structure is shown to determine which type of equilibrium obtains: the "ends" are a strict majority when the marginal cost per student of the private university's higher quality is small enough to make the private university attractive and the "middle" is a strict majority when this marginal cost is high enough to make the private university rather unattractive. When the quality differential between the two universities is large, a relatively small decrease of the marginal cost of quality per student or/and a small increase of the cost per student at the public university, that is a relative decrease of the private education cost with respect to the public one, may have in our framework the effect of leading to an important rise of the public tuition fee by leading to a majority reversal, the "ends" winning a strict majority against the "middle". Finally, we show that the equilibrium public tuition fee exceeds the optimal one when the "ends" are a strict majority and falls short of it when the "middle" is a strict majority: majority voting leads either to overshoot or to undershoot the optimum.

The remainder of the paper is organized as follows. Section 2 introduces the model. In Section 3, we solve the game and provide comparative statistics. We conclude in Section 4. All proofs are given in Appendix A. 


\section{The model}

We consider a model with two different universities a public and a private one and where agents choose to train in the public or private university or not to train at all. This choice is made by comparing the lifetime benefits from training (additional discounted income) and the tuition fees to be paid initially. We assume that the tuition fee of the public university is fixed by majority voting while that of the private one is determined by profit maximization.

The universities. The State university proposes a training program delivering a quality $q_{S}=1$ and the private one offers training yielding a quality $q_{P}>1$ with respective tuition fees $t_{S}$ and $t_{P}$ and unit costs of training $c_{S}=c<1$ and $c_{P}=c+m\left(q_{P}-1\right), m>0$. We suppose that the tuition fee at the State university cannot be negative.

Agents. There is a continuum of agents, the mass of which is normalized to $1^{7}$. If an agent does not train, he/she will earn thereafter a fixed lifetime income, which is independent of his/her type and which we normalize to 0 . When choosing to train, a type $\theta$ - agent earns a type-dependent income $\theta q$ once trained, where $q$ is the quality of training and $\theta$ is distributed on the interval $[0,1]$. Notice that $\theta$ represents the additional lifetime income which the type $\theta$-agent will derive thereafter from training at the public university (where $q_{S}=1$ ) or, equivalently, the lifetime benefit he/she will obtain from a marginal increase in educational quality. We suppose that a type 0 -agent chooses not to train when $t_{S}=0$, namely when there is no strictly positive benefit from training.

All agents, whether skilled or not, pay during the training period a uniform $\operatorname{tax}^{8}$ per head $\tau$ which is fixed so as to balance the public budget, i.e. to cover the difference between the costs of training at the public university and the tuition fees which are paid by the students. The tax level is fixed before the students may be able to derive any benefit from higher education and, given that the agents' types are unobservable ex ante, is independent of the future benefits they will derive from training. This provides a rationale for the uniformity of the $\operatorname{tax}^{9}$.

Hence the payoffs of an unskilled agent, a skilled agent in the State university and a skilled agent in the private one are respectively,

$$
\begin{gathered}
U^{u}(\tau)=-\tau, \\
U_{S}^{s}\left(\theta, t_{S}\right)=\theta-t_{S}-\tau,
\end{gathered}
$$

\footnotetext{
${ }^{7}$ We may consider that a typical "agent" is a family in which the parents are purely altruistic in the sense that when voting they fully share the interest of their children.

${ }^{8}$ Subsidy if negative.

${ }^{9}$ More precisely the important assumption is that the amount of the tax paid by the agent (family) must be independent of the student's type. The amount of the tax may be dependent on exogenous initial family income $y$ provided, there is no correlation between initial family income $y$ and the student's type $\theta$.
} 
and

$$
U_{P}^{s}\left(\theta, t_{P}\right)=\theta q_{P}-t_{P}-\tau .
$$

Training expenditures at the State university are paid by the State, which receives the corresponding training fees and balances its budget by adjusting the tax level, so that

$$
\left(\frac{t_{P}-t_{S}}{q_{P}-1}-t_{S}\right)\left(t_{S}-c_{S}\right)=-\tau .
$$

Since there is no natural assumption on the way in which they could be distributed between domestic agents, we assume for the sake of simplicity that the profits of the private university go to non-voters (foreigners). For many countries, assuming that the alternative to public higher education is to go to a foreign university is not a bad assumption ${ }^{10}$.

The game. The timing of the game is such that:

- in stage 1 , universities fix their tuition fees; the public university selects the tuition fee which follows from majority voting, while the private university's tuition fee is determined by profit maximization.

- in stage 2 , agents choose to train in the public university or in the private one or not to train at all. The tax per head is adjusted so as to balance the public budget.

It is assumed that voters, when deciding upon the public university's tuition fee, hold rational expectations. They perfectly anticipate how, given the tuition fees at the private and public universities, the agents divide into three groups: those who don't train, those who train at the public university and those who train at the private university. They accordingly deduce the value of the income tax which will follow from any couple of tuition fees. As usual, the game is solved backward.

\section{The equilibrium}

In this section we solve the game by backward-induction. At the second stage, agents choose to train in the public university or in the private one or not to train at all. At the first stage, the private university fixes its tuition fee $t_{P}$ in order to maximize its profit while the State university fixes the tuition fee $t_{S}$ by majority voting. Private university and voters rationally anticipate the second-period outcomes.

\footnotetext{
${ }^{10}$ France, for instance, has no really important private university.
} 


\subsection{Second-stage training decisions}

The type $\theta$-agent indifferent between training at the State university and not training at all is given by $\theta=t_{S}$, whereas the one indifferent between training at the State university and training at the private one is given by $\theta=\frac{t_{P}-t_{S}}{q_{P}-1}$. This implies that agents with low revenues $(\theta)$ prefer not to train while those with high revenues prefer to train in the private university. The middle class of agents prefer to train in the State university. Thus the respective demands for training at the private and the State universities are respectively

$$
D_{P}=\left(1-\frac{t_{P}-t_{S}}{q_{P}-1}\right)
$$

and

$$
D_{S}=\left(\frac{t_{P}-t_{S}}{q_{P}-1}-t_{S}\right)
$$

For the sake of simplicity, we shall only consider the case where the RHS of (2) and (3) take on positive equilibrium values, i.e. the case where both universities are active at equilibrium. Extending our results to cover the case where one university is closed would be straightforward but cumbersome.

\subsection{First-stage tuition fees' determination}

The private university's tuition fee follows simply from profit maximization, given the public tuition fee $t_{S}$. Its best reply function is continuous and increasing in $t_{S}$ :

$$
t_{P}\left(t_{S}\right)=\frac{1}{2}\left(t_{S}+c+(m+1)\left(q_{P}-1\right)\right) .
$$

On the other hand, the value of $t_{S}$ is determined by majority voting as a best reply to $t_{P}$.

In order to understand this determination, it is necessary to determine precisely what is a type $\theta$ - indirect utility function as a function of $t_{S}$. Substituting in the utilities of the three types of agents the value of $\tau$ from equation (1), we obtain

$$
U^{u}\left(t_{S}\right)=\left(\frac{t_{P}-t_{S}}{q_{P}-1}-t_{S}\right)\left(t_{S}-c_{S}\right)
$$

for a type $\theta$-agent who does not train,

$$
U_{S}^{s}\left(t_{S}\right)=\theta-t_{S}+\left(\frac{t_{P}-t_{S}}{q_{P}-1}-t_{S}\right)\left(t_{S}-c_{S}\right)
$$

for a type $\theta$-agent who trains at the public university, and

$$
U_{P}^{s}\left(t_{S}\right)=\theta q_{P}-t_{P}+\left(\frac{t_{P}-t_{S}}{q_{P}-1}-t_{S}\right)\left(t_{S}-c_{S}\right),
$$


for a type $\theta$-agent who trains at the private university. Notice that $U^{u}\left(t_{S}\right)$, $U_{P}^{s}\left(t_{S}\right)$ and $U_{S}^{s}\left(t_{S}\right)$ are concave and reach their maxima respectively at $t_{S}^{s P}=$ $t_{S}^{u}=\frac{q_{P} c+t_{P}}{2 q_{P}}$ and $t_{S}^{s S}=\frac{q_{P}(c-1)+t_{P}+1}{2 q_{P}}$, irrespective of the agent's type $\theta$.

Notice in addition that choosing or not to train and, in the former case, choosing where to train, is an endogenous function of the public tuition fee $t_{S}$ : people do not belong ex ante to one of the three possible groups.

We distinguish two cases. The first occurs when $\theta \in\left[0, \frac{t_{P}}{q_{P}}[\right.$, or, equivalently, $U_{P}^{s}\left(t_{S}\right)<U^{u}\left(t_{S}\right)$ : agents always prefer not to train rather than to train at the private university, so that their only choice is between training at the public university or not training at all. Hence the utility these agents $\theta \in\left[0, \frac{t_{p}}{q_{p}}[\right.$ is a piece-wise continuous function given by:

$$
U_{\theta}\left(t_{S}\right)= \begin{cases}U_{S}^{s}\left(t_{S}\right), & \text { iff } t_{S} \leq \theta \\ U^{u}\left(t_{S}\right), & \text { iff } t_{S}>\theta\end{cases}
$$

This function is double-peaked, with local maxima at $t_{S}^{s P}=t_{S}^{u}$ and $t_{S}^{s S}$, when $\theta \in\left(t_{S}^{s S}, t_{S}^{u}\right)$ and single-peaked otherwise (see Figures 3, 4 and 5 in Appendix).

The second case occurs when $\left.\theta \in] \frac{t_{P}}{q_{P}}, 1\right]$, or, equivalently, $U^{u}\left(t_{S}\right)<U_{P}^{s}\left(t_{S}\right)$ : agents always prefer to train at the private university rather than not to train at all so that their only choice is between training at the State university or at the private one. Hence the utility of agents $\theta$ in $\left.] \frac{t_{p}}{q_{p}}, 1\right]$ is a piece-wise continuous function given by:

$$
U_{\theta}\left(t_{S}\right)= \begin{cases}U_{S}^{s}\left(t_{S}\right), & \text { iff } t_{S} \leq t_{P}-\theta\left(q_{P}-1\right) ; \\ U_{P}^{s}\left(t_{S}\right), & \text { iff } t_{S}>t_{P}-\theta\left(q_{P}-1\right) .\end{cases}
$$

This function is double-peaked, with local maxima at $t_{S}^{s P}=t_{S}^{u}$ and $t_{S}^{s S}$, when $t_{S}^{s S}<t_{P}-\theta\left(q_{P}-1\right)<t_{S}^{s P}$ and single-peaked otherwise (see Figures 6, 7 and 8 in Appendix).

It follows from above that we cannot rely on the median voter theorems to ascertain the existence of a Condorcet winner. On one hand, we have just seen that voters' preferences are not always single-peaked: double-peakedness obtains for large intervals of values of $\theta$. On the other hand, the preferences do not either satisfy the single-crossing property: the most preferred value of $t_{S}$ is not a monotonic function of the voter's type $\theta$. More precisely, voters with respectively low and large values of $\theta$, who don't go to the public university ${ }^{11}$, favor a high value $t_{S}^{s P}=t_{S}^{u}$ of the public university's tuition fee while voters with intermediate values of $\theta$, who go to the public university, favor a low value $t_{S}^{s S}$ of the public university's tuition fee.

Lemma 1 nevertheless shows that, for every value of $t_{P}$, there is a Condorcet winner which is either $t_{S}^{s P}=t_{S}^{u}$ or $t_{S}^{s S}$. A straightforward corollary is that one only needs to compare $t_{S}^{s P}=t_{S}^{u}$ and $t_{S}^{s S}$ to determine which of the two is the Condorcet winner.

\footnotetext{
${ }^{11}$ The former because they don't study at any university, the latter because they go to the private university.
} 
Lemma 1 For a given $t_{P}$, there is a Condorcet winner which is either

$$
t_{S}^{s P}=t_{S}^{u}=\frac{q_{P} c+t_{P}}{2 q_{P}}
$$

or

$$
t_{S}^{s S}=\frac{q_{P}(c-1)+t_{P}+1}{2 q_{P}} .
$$

The proof of Lemma 1 is very long but it makes a very simple point. Suppose that some $a \neq t_{S}^{s P}$ and $\neq t_{S}^{s S}$ is a Condorcet winner, i.e. that there is a majority for $a$ versus $t_{S}^{s P}$ and a majority for $a$ versus $t_{S}^{s S}$. We show in the Proof that, if there is a majority for $a$ versus $t_{S}^{s P}$, there is an even larger majority for $t_{S}^{s S}$ versus $t_{S}^{s P}$. We also show that if there is a majority for $a$ versus $t_{S}^{s S}$, there is an even larger majority for $t_{S}^{s P}$ versus $t_{S}^{s S}$. Accordingly, assuming that some $a$ $\neq t_{S}^{s P}$ and $\neq t_{S}^{s S}$ is a Condorcet winner leads to a contradiction.

Now, the same type of argument shows that if there is a majority for $t_{S}^{s P}$ (resp. $t_{S}^{s S}$ ) versus $t_{S}^{s S}\left(\operatorname{resp} . t_{S}^{s P}\right)$, then $t_{S}^{s P}\left(\operatorname{resp} . t_{S}^{s S}\right)$ is the Condorcet winner. For suppose this not true and there is some $a$ which defeats $t_{S}^{s P}$ (resp. $t_{S}^{s S}$ ): by the above argument $t_{S}^{s S}\left(\operatorname{resp} . t_{S}^{s P}\right)$ would defeat $t_{S}^{s P}$ (resp. $\left.t_{S}^{s S}\right)$, a contradiction. Accordingly, we only need to compare $t_{S}^{s S}$ and $t_{S}^{s P}$.

Lemma 2 For a given $t_{P}$, the Condorcet winner is $t_{S}^{s P}=t_{S}^{u}$ when $t_{P}<$ $\frac{1}{2}\left(q_{P}(2 c+1)-1\right)$ and it is $t_{S}^{s S}$ when $t_{P}>\frac{1}{2}\left(q_{P}(2 c+1)-1\right)$. When $t_{P}=$ $\frac{1}{2}\left(q_{P}(2 c+1)-1\right)$, there is a tie vote between the two.

When there is a majority of votes, the public university selects the Condorcet winner. In the case of a tie vote, we suppose that the public university randomizes, choosing $t_{S}^{u}$ with probability $\lambda$ and $t_{S}^{s S}$ with probability $1-\lambda$.

From Lemmas 1 and 2, the voters' reaction function is discontinuous at $t_{P}=\frac{1}{2}\left(q_{P}(2 c+1)-1\right)$ since $t_{S}^{s S}<t_{S}^{s P}=t_{S}^{u}$. This is illustrated in Figure 1 where it can be seen that there are three cases. The first occurs when the reaction functions intersect for a value of $t_{P}<\frac{1}{2}\left(q_{P}(2 c+1)-1\right)$ : the extremes, which respectively don't go to any university and go to the private university, are a majority and select a high tuition fee for the public university: this is the "high tuition fees" equilibrium. The second occurs when the reaction functions intersect for a value of $t_{P}>\frac{1}{2}\left(q_{P}(2 c+1)-1\right)$ : the middle class which opts for the public university is a majority and selects a low tuition fee for the public university: this is the "low tuition fees" equilibrium. The third case is the one when the reaction functions do not intersect so that no pure strategy equilibrium exists. In the latter case, we see below that a mixed strategy equilibrium exists where votes tie.

\subsection{The high tuition fees equilibrium: When the ends de- feat the middle}

In this case, the extremes represent a majority and vote for $t_{S}^{u}$. Proposition 1 characterizes the equilibrium outcome. 


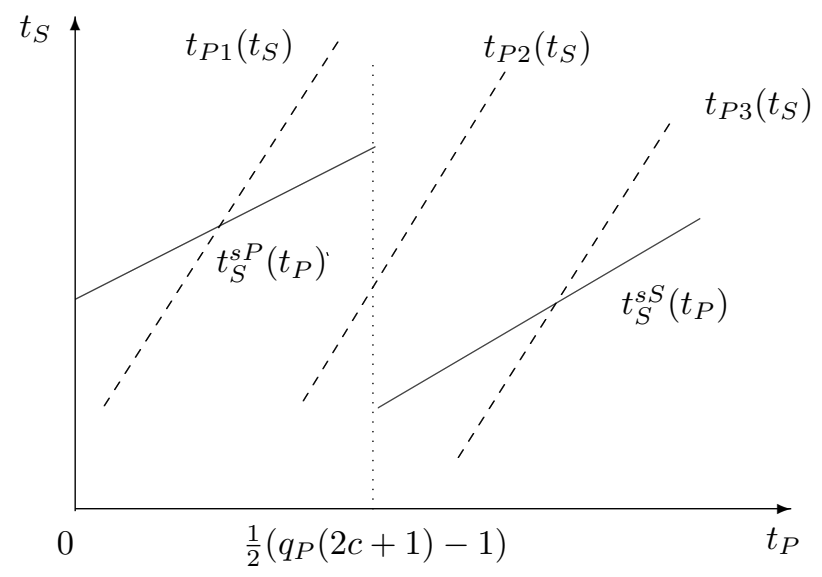

Figure 1: The tuition fees equilibria

Proposition 1 For $\forall c \leq \frac{1}{2}$, there is a "high tuition fees equilibrium", with a majority of votes at the ends, such that both universities are open, iff $m<$ $2 c-\frac{1}{4 q_{P}}$. At equilibrium the tuition fees are given by,

$$
t_{S}^{*}=\frac{\left(q_{P}-1\right)(1+m)+c\left(2 q_{P}+1\right)}{4 q_{P}-1}>c, t_{P}^{*}=\frac{q_{P}\left(2(1+m)\left(q_{P}-1\right)+3 c\right)}{4 q_{P}-1},
$$

Notice that, equivalently, at this equilibrium

$$
t_{S}^{*}=\frac{\left(q_{P}-1\right)+2 q_{P} c_{S}+c_{P}}{4 q_{P}-1}
$$

At a high tuition fees equilibrium any increase in the unit costs of higher education result in a higher public tuition fee as well as in a higher private tuition fee. Interestingly,

$$
\frac{\partial t_{S}^{*}}{\partial c_{S}}=\frac{2 q_{P}}{4 q_{P}-1} \in\left(\frac{1}{2}, \mathbf{1}\right)
$$

i.e. an increase in the cost of education at the public university is only partially passed on to students.

From the above Proposition, the agents who don't train, together with the ones who study at the private university, form a majority when the marginal cost of providing the highest educational quality is low enough, i.e. when $m$ is small, so that the private university is attractive enough. Indeed, a smaller value of $m$ implies lower equilibrium tuition fees for both universities but the private university's tuition fee decreases more than the public university's one. It follows that more people choose to train at the private university and that less people choose not to train. However, the former effect dominates the latter, so that the number of people training at the public university is lower. 


\subsection{The low tuition fees equilibrium: When the middle defeats the ends}

In this case, there is a majority of voters (the "middle class") who vote for $t_{S}^{s S}$. Proposition 2 provides the equilibrium outcome.

Proposition 2 For $c<\frac{2 q_{P}-1}{4 q_{P}}$, there is a "low tuition fees equilibrium", with a majority in the middle, such that both universities are open, iff $m \in(2 c+$ $\left.\frac{1}{4 q_{P}}, 1-\frac{c}{2 q_{P}-1}\right)$. At this equilibrium the tuition fees are given by

$t_{S}^{*}=\frac{\left(q_{P}-1\right)(m-1)+c\left(2 q_{P}+1\right)}{4 q_{P}-1}, t_{P}^{*}=\frac{1+q_{P}\left(2(1+m)\left(q_{P}-1\right)+3 c-1\right)}{4 q_{P}-1}$,

The condition $c<\frac{2 q_{P}-1}{4 q_{P}}$ is to ensure that the interval $\left(2 c+\frac{1}{4 q_{P}}, 1-\frac{c}{2 q_{P}-1}\right)$ is non-void.

Notice that, equivalently, at this equilibrium

$$
t_{S}^{*}=\frac{2 q_{P} c_{S}+c_{P}-\left(q_{P}-1\right)}{4 q_{P}-1} .
$$

At a low tuition fees equilibrium any increase in the unit costs of higher education result in a higher public tuition fee as well as in a higher private tuition fee. Interestingly, as in a high tuition fee equilibrium,

$$
\frac{\partial t_{S}^{*}}{\partial c_{S}}=\frac{2 q_{P}}{4 q_{P}-1} \in\left(\frac{1}{2}, \mathbf{1}\right)
$$

i.e. here as well an increase in the cost of education at the public university is only partially passed on to students.

From the above Proposition, the agents who train at the public university form a majority when the marginal cost $m$ of providing the highest educational quality is high enough, so that there are few people who train at the private university. Indeed, a higher value of $m$ implies larger equilibrium tuition fees for both universities but the private university's tuition fee increases more than the public university's one. It follows that less people choose to train at the private university and that more people choose not to train. However, the former effect dominates the latter, so that the number of people training at the public university is larger.

The Proposition only deals with the case when there is positive demand for training at both universities. For values of $m$ larger than $1-\frac{c}{2 q_{P}-1}$, it is possible to show that the public university is the only one to be open and a majority of voters choose to train there, voting accordingly for a low tuition fee. This would be lengthy and would not add very much to the intuition so it is left to the reader. 


\subsection{Mixed equilibria: When votes tie}

When there is a tie vote the public university has been assumed to choose $t_{S}^{u}$ with a probability $\lambda$ and $t_{S}^{s S}$ with a probability $(1-\lambda)$. Proposition 3 characterizes the equilibrium outcome in this case.

Proposition 3 For $\forall c<\frac{2 q_{P}-1}{4 q_{P}}$, there are mixed equilibria in which both universities are open iff $m \in\left[2 c-\frac{1}{4 q_{P}}, 2 c+\frac{1}{4 q_{P}}\right]$ The private and public universities respectively select

$$
t_{P}^{*}=\frac{1}{2}\left(q_{P}(2 c+1)-1\right), \text { with probability } 1
$$

and

$$
\begin{aligned}
& t_{S}^{*}=c+\frac{q_{P}-1}{4 q_{P}}, \text { with probability } \lambda^{*}, \\
& t_{S}^{*}=c-\frac{q_{P}-1}{4 q_{P}}, \text { with probability } 1-\lambda^{*},
\end{aligned}
$$

where

$$
\lambda^{*}=\frac{1}{2}\left(1+4 q_{P}(2 c-m)\right) .
$$

Corollary 4 The expected public tuition fee when votes tie equals

$$
\begin{aligned}
t_{S}^{* e} & =2 q_{P} c-\left(c+m\left(q_{P}-1\right)\right) \\
& =2 q_{P} c_{S}-c_{P} .
\end{aligned}
$$

Interestingly, it is increasing in the unit cost of public education but decreasing in the unit cost of private education and, as far as it is positive ${ }^{12}$, increases in the case of increases of both. This is because when the latter decreases the private university becomes more attractive, raising the probability of a high public tuition fee through a "tipping of majority" effect. The impact of an increase in $c_{S}$ on expected public tuition fees is all the more important as it not only directly raises the public tuition fee in all occurrences (direct cost effect) but also raises the probability of the occurrence of the high tuition fee (political effect). More precisely

$$
\frac{\partial t_{S}^{* e}}{\partial c_{S}}=2 q_{P}>2
$$

i.e. the resulting increase in the expected public tuition fee is more than twice any increase in the cost of public higher education.

In the following subsection we provide some comparative statistics relative to the three types of equilibria.

${ }^{12} \mathrm{~A}$ sufficient positiveness condition is $c>\frac{1}{4}\left(1-\frac{1}{q_{P}}\right)$. 


\section{Optimal vs equilibrium public tuition fees}

Stiglitz (1994) main purpose was to determine whether majority voting leads to an underprovision or an overprovision of public education. In this paper we have focused on the determination of equilibrium public tuition fees which result from majority voting. A comparison with their optimal value is of interest.

Let us first determine the aggregate social surplus by summing the agents' utilities $^{13}$ as given by (5) for $\theta \in\left[0, t_{S}\right]$, by (6) for $\theta \in\left[t_{S}, \frac{t_{P}-t_{S}}{q_{P}-1}\right]$ and by (7) for $\theta \in\left[\frac{t_{P}-t_{S}}{q_{P}-1}, 1\right]$. We obtain:

$$
W=\frac{q_{P}^{2}-q_{P}\left(1+2 t_{P}-2 c t_{S}+t_{S}^{2}\right)+t_{P}\left(2-2 c+t_{P}\right)}{2\left(q_{P}-1\right)} .
$$

Let us now substitute for $t_{P}$ in the above equation its value for the private university's reaction function (4). $W$ is maximized for

$$
t_{S}^{O p t}=\frac{q_{P}(4 c+m-1)-(m+c-1)}{4 q_{P}-1} .
$$

$t_{S}^{O p t}$ is increasing in $c$ and $m$. It is increasing in $q_{P}$ if $m>1$ and decreasing in $q_{P}$ in the opposite case.

To set the stage for a comparison between the optimal and equilibrium values of the public tuition fee, it is worthwhile to see how the latter changes with the value of $m$. This relationship is pictured in Figure 2 below, together with the optimal public tuition fee. The equilibrium public tuition fee ${ }^{14}$ is an increasing function of $m$ both low values of $m$ (for which the "high tuition fees equilibrium" obtains) and for large ones (for which the "low tuition fees equilibrium obtains"). This follows from a strategic effect: an increase in $m$ raises directly the private tuition fee and, given strategic complementary between the tuition fees, this results in a higher equilibrium value of the public tuition fee. For values in between, the expected public tuition fee is decreasing in $m$, simply because an increase of $m$ raises the probability that the public university will choose the lowest tuition fee $\left(t_{S}^{s S}\right)$. This is a "tipping of majority effect". The range $\left[2 c-\frac{1}{4 q_{P}}, 2 c+\frac{1}{4 q_{P}}\right]$, over which one obtains a decreasing relationship, is itself the smaller the largest is the private educational quality $q_{P}$.

It is now easy to compare the optimal value from (8) with the equilibrium ones from the three Propositions above. Straightforwardly the equilibrium public tuition fee exceeds the optimal one by $\frac{c}{2 q_{P}}$ when the ends are a strict majority and falls short of it by $\frac{1-c}{2 q_{P}}$ when the middle gains a strict majority ${ }^{15}$. So the gap between equilibrium and optimal values is larger in the majority at the ends

\footnotetext{
${ }^{13}$ Remember that the private university's profits are not included in the aggregate social surplus.

${ }^{14}$ In the mixed equilibrium case, we consider the expected equilibrium public tuition fee.

${ }^{15}$ Notice that the slopes of $t_{S}^{*}$ and $t_{S}^{O p t}$ with respect to $m$ are identical $\left(=\frac{q_{P}-1}{4 q_{P}-1}\right)$ in the intervals $\left[0,2 c-\frac{1}{4 q_{P}}\right]$ and $\left[2 c+\frac{1}{4 q_{P}}, 1-\frac{c}{2 q_{P}-1}\right]$.
} 
case when $c<\frac{1}{2}$ and in the majority at the middle case when $c>\frac{1}{2}$. Moreover, there is a critical value of $m$, in the range for which a mixed equilibrium prevails, such that the expected equilibrium tuition fee equals the optimal one. This value obtains as:

$$
\widehat{m}=2 c+\frac{1-2 c}{4 q_{P}} .
$$

It is is easy to check that $\widehat{m} \in\left(2 c-\frac{1}{4 q_{P}}, 2 c+\frac{1}{4 q_{P}}\right)$.

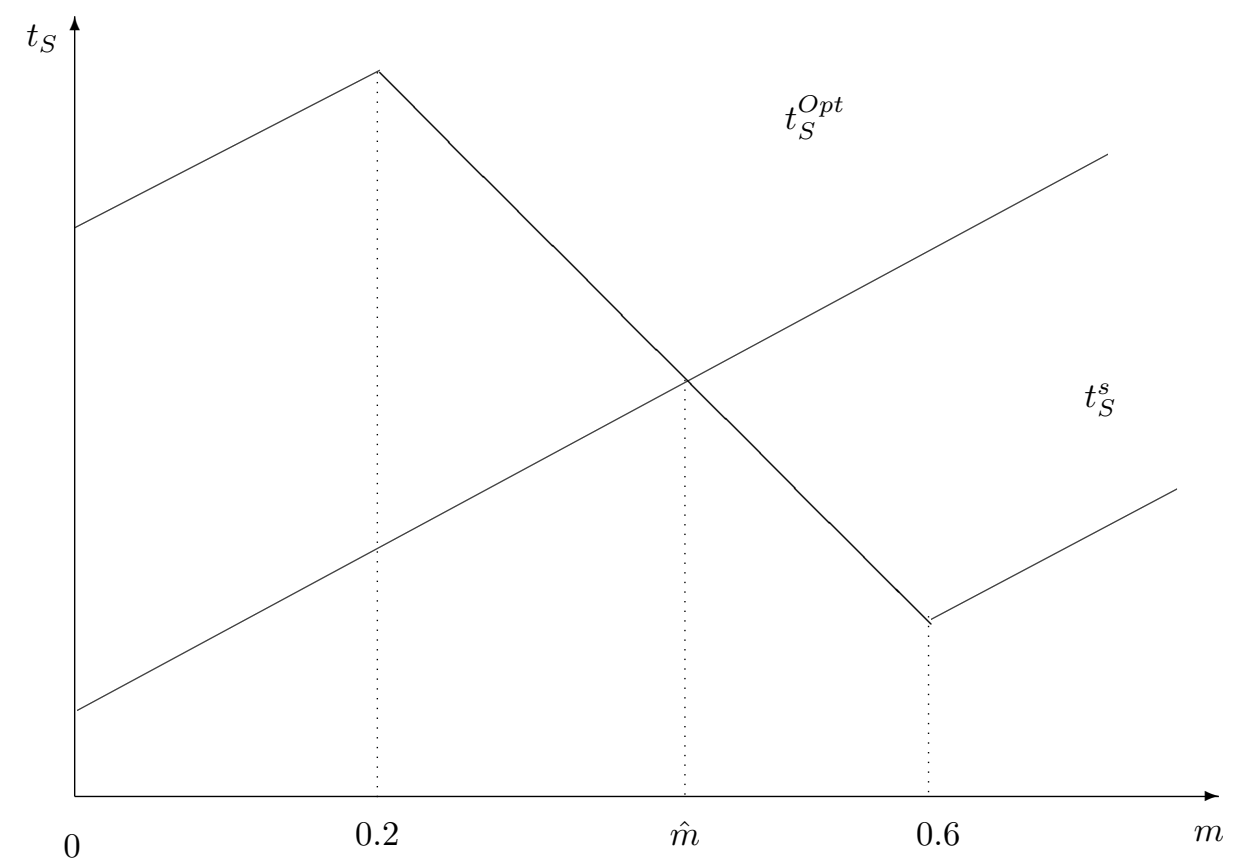

Figure 2: $t_{S}^{s *}$ and $t_{S}^{O p t}$ as functions of $m$

We can conclude that the (expected) equilibrium public tuition fee is greater that the optimum one when $m<\widehat{m}$ and smaller in the opposite case. The tipping of majority which occurs when the marginal cost of educational quality at the private university decreases entails a switch from a too small to a too high public tuition fee.

\section{Conclusion}

In this paper, we have studied the joint determination of tuition fees at a public university, through majority voting, and a private university, through profit maximization. We have proved the existence of an equilibrium which is one of three types, according to the cost structure. In the first one, when the marginal 
cost per student $m$ of the private university's superior quality is low, the "ends" are a strict majority and the equilibrium level of the public tuition fee exceeds its optimal level. In the second, when $m$ is high, the "middle is a strict majority the equilibrium level of the public tuition fee falls short of its optimal level. In the third, for intermediate values of $m$, votes tie and the public university randomizes between a tuition fee above and a tuition fee below its optimal level.

Our paper may help to understand the process which has led to very large increases in public tuition fees in several countries. Martin's (2002) claim that they result from quasi-mechanical pass-on to students of increases in training costs is not confirmed by our results: under stable majorities, only a fraction of increases in public tuition expenditures is passed on to students, so that non-dramatic increases in training costs cannot result in dramatic increases in public tuition fees. On the contrary, moderate evolutions of the training $\operatorname{costs}^{16}$ may result into dramatic variations of the public tuition fee when they trigger majority reversals. More precisely, in the latter case, large increases in the public tuition fee may occur then as a consequence of moderate increases of the public training cost and/or the private training cost.

\section{References}

[1] Barzel, Y. (1973), Private schools and public school finance, Journal of Political Economy, 81(1), 174-186.

[2] Bearse, P., Glomm, G. and Patterson, D.M. (2005), Endogenous public expenditures on education, Journal of Public Economic Theory, 7(4), 561-577.

[3] De la Croix, D. and Doepke, M. (2009), To segragate or to integrate: education politics and democracy, Review of Economic Studies, 76, 597-628.

[4] Desrochers D.M. and S Hulburt (2016), Trends in College Spending: 20032013, Delta Cost Project at American Institutes for Research.

[5] Epple, D. and Romano, R. (1996a), Ends against the middle: Determining public provision when there are private alternatives, Journal of Public Economics, 62, 297-325.

[6] Epple, D. and Romano, R. (1996b), Public provision of private goods, Journal of Political Economy, 104, 57-84.

[7] Glomm, G. and Ravikumar, B. (1996), Opting out of publicly provided services: A majority voting result, Social Choice and Welfare, 15, 187-199.

\footnotetext{
${ }^{16}$ The cost incidence of the "increasing time given to professors for scholarship and other activities" seems to have been mitigated by the increased use of nonpermanent, part-time teachers (see Desrochers and Hulburt (2016) for the US case).
} 
[8] Marcucci, P.N. and Johnstone, D.B. (2007), Tuition Fee Policies in a Comparative Perspective: Theoretical and Political Rationales, Journal of Higher Education Policy and Management, 29, 25-40.

[9] Martin, R.E. (2002), Why Tuition Costs Are Rising So Quickly, Challenge, 45, 88-108.

[10] Stiglitz, J.E. (1974), The demand for education in public and private school systems, Journal of Public Economics 3, 349-385.

\section{Appendix}

Proof of Lemma 1. In order to prove that $t_{S}^{s S}$ and $t_{S}^{s P}=t_{S}^{u}$ are the only possible Condorcet winners we prove that all other values of $t_{S}$ are defeated by $t_{S}^{s S}$ or $t_{S}^{s P}=t_{S}^{u}$, i.e. any other values of $t_{S}$ might be a majority.

As explained above in Subsection 3.2 the agents' utility varies according to the value of $\theta$. We distinguish two cases when $\theta \in\left[0, \frac{t_{P}}{q_{P}}[\right.$ (Figures 3,4 and 5) and $\left.\theta \in] \frac{t_{P}}{q_{P}}, 1\right]$ (Figures 6, 7 and 8):

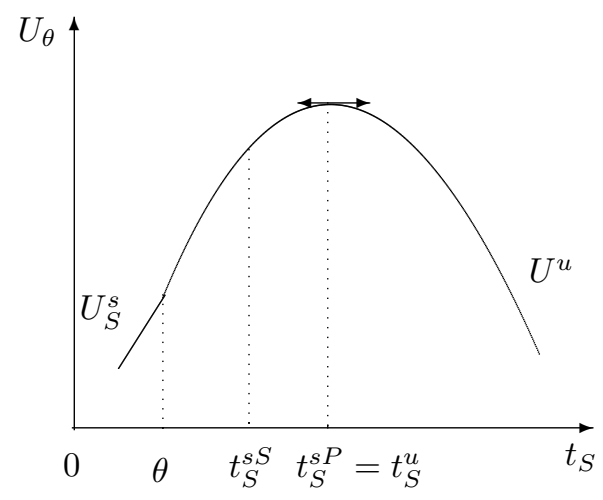

Figure 3: Case (i)

According to Figures 3, 4, 5, 6, 7 and 8 it is clear that all values of $t_{S}<t_{S}^{s S}$ are always defeated by $t_{S}^{s S}$ and that all values of $t_{S}>t_{S}^{s P}=t_{S}^{u}$ are always defeated by $t_{S}^{s P}=t_{S}^{u}$. Hence there is no value of $t_{S}$ in $\left[0, t_{S}^{s S}[\right.$ or $] t_{S}^{s P}=t_{S}^{u},+\infty[$ which might be a Condorcet winner. However things are more subtle for values of $t_{S}$ in $\left[t_{S}^{s S}, t_{S}^{s P}=t_{S}^{u}\right]$, this is the case for Figures 4 and 7 .

Here the idea is to prove that if one value of $t_{S}$, denoted $a$, in $\left[t_{S}^{s S}, t_{S}^{s P}\right]$ defeats $t_{S}^{s S}$ it is necessarily defeated by $t_{S}^{s P}$ and vice versa, thus, there is no 


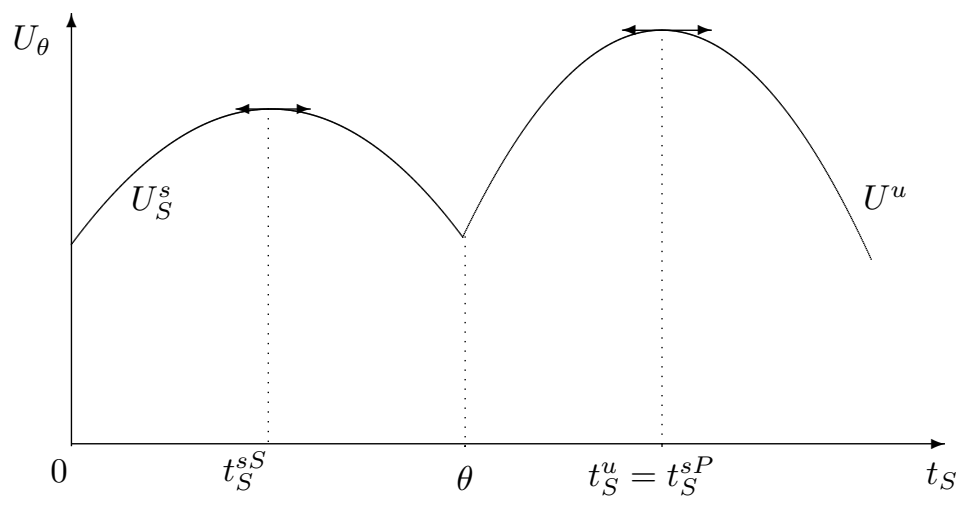

Figure 4: Case (ii)

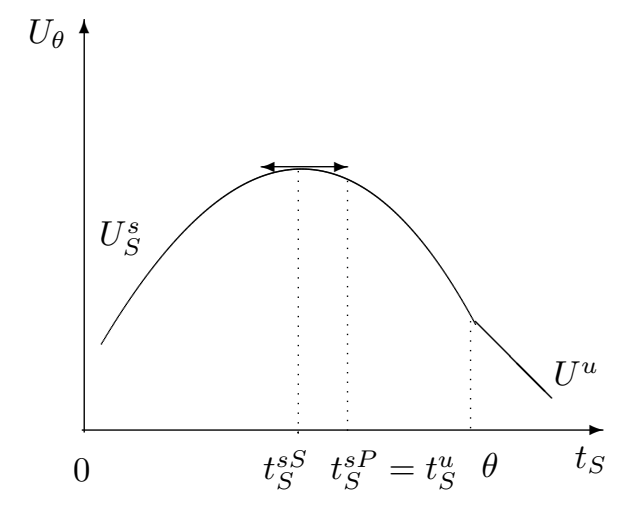

Figure 5: Case (iii)

value of $t_{S} \in\left[t_{S}^{s S}, t_{S}^{s P}\right]$ which might be a Condorcet winner.

We start first by comparing $a \in\left[t_{S}^{s S}, t_{S}^{s P}\right]$ to $t_{S}^{s S}$ and determine conditions under which $a$ is a majority.

- For the cases (i) and (iv) (Figures 3 and 6), i.e. the utility function is single-peaked at $t_{S}^{s P}$, it is clear that all voters choose $a$.

- For the cases (iii) and (vi) (Figures 5 and 8), i.e. the utility function is single-peaked at $t_{S}^{s S}$, all voters choose $t_{S}^{s S}$.

- For the cases (ii) and (v) (Figures 4 and 7), i.e. the utility function has 


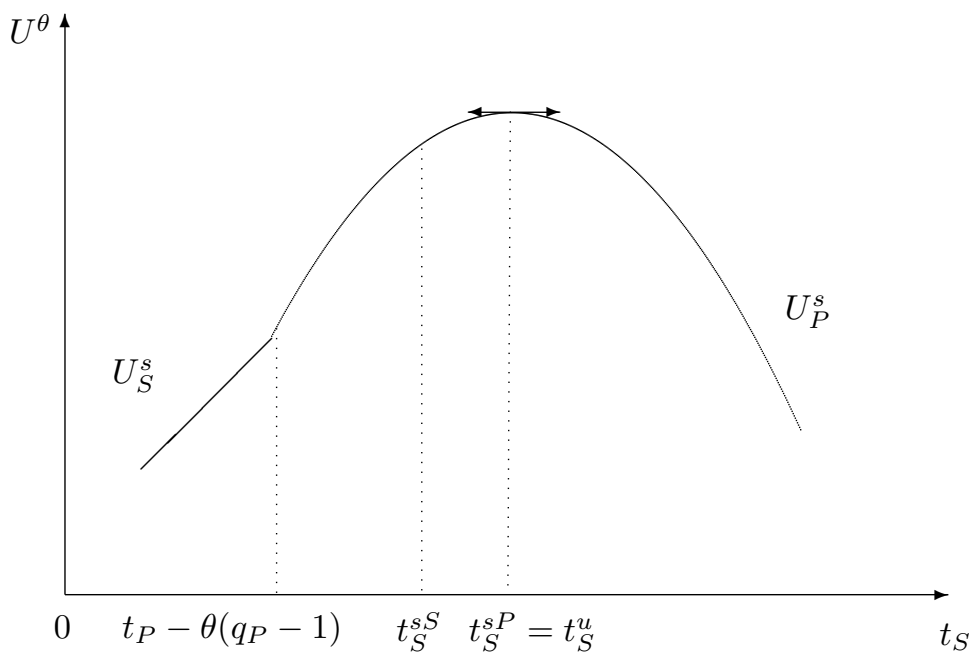

Figure 6: Case (iv)

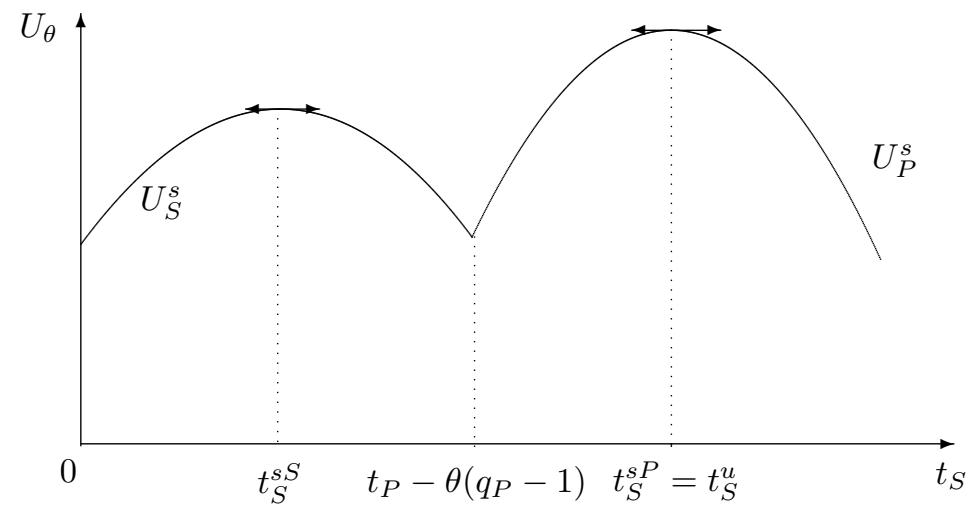

Figure 7: Case (v)

two peaks at $t_{S}^{s S}$ and $t_{S}^{s P}$, we compare respectively $U_{S}^{s}\left(t_{S}^{s S}\right)$ to $U^{u}(a)$ and 


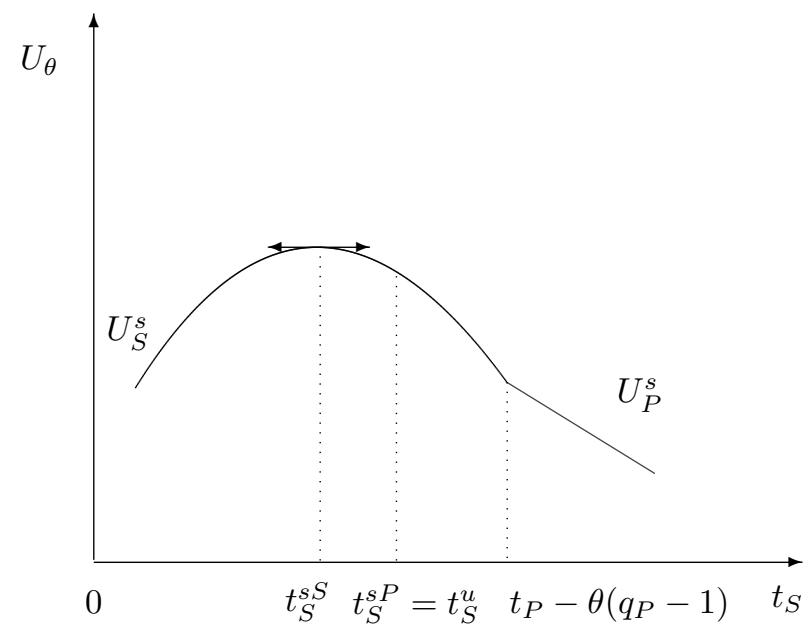

Figure 8: Case (vi)

$U_{S}^{s}\left(t_{S}^{s S}\right)$ to $U_{P}^{s}(a)$. As depicted in Figures 9 and 10, We denote respectively $\theta_{1}(a)$ and $\theta_{2}(a)$ the values of $\theta$ at which $U_{S}^{s}\left(t_{S}^{s S}\right)=U^{u}(a)$ and $U_{S}^{s}\left(t_{S}^{s S}\right)=$ $U_{P}^{s}(a)$.

$$
\theta_{1}(a)=-\frac{\left(1-2 c+(c-2 a)^{2}\right) q_{P}^{2}+\left(1+t_{P}\right)^{2}+2 q_{P} t_{P}(c-1+(c-2 a-1))}{4 q_{P}\left(q_{P}-1\right)},
$$

$\theta_{2}(a)=\frac{\left(4 a(a-c)+(c-1)^{2}+4 t_{P}\right) q_{P}^{2}+\left(2(c-1)+2 t_{P}(c-3-2 a)\right) q_{P}+\left(t_{P}+1\right)^{2}}{4 q_{P}\left(q_{P}-1\right)^{2}}$.

Then in order to determine the choice of voters for each case we compare $\theta_{1}(a)$ and $\theta_{2}(a)$ to $\frac{t_{P}}{q_{P}}$ as follows:

$$
\begin{aligned}
\theta_{1}(a)-\frac{t_{P}}{q_{P}} & =-\frac{\left(1-2 c+(c-2 a)^{2}\right) q_{P}^{2}+\left(t_{P}-1\right)^{2}+2 q_{P}\left(c-1+(1-2 a+c) t_{P}\right)}{4 q_{P}\left(q_{P}-1\right)} \\
& =\frac{P(a)}{4 q_{P}\left(q_{P}-1\right)} \\
\theta_{2}(a)-\frac{t_{P}}{q_{P}} & =\frac{\left(1-2 c+(c-2 a)^{2}\right) q_{P}^{2}+\left(t_{P}-1\right)^{2}+2 q_{P}\left(c-1+(1-2 a+c) t_{P}\right)}{4 q_{P}\left(q_{P}-1\right)} \\
& =\frac{R(a)}{4 q_{P}\left(q_{P}-1\right)}
\end{aligned}
$$




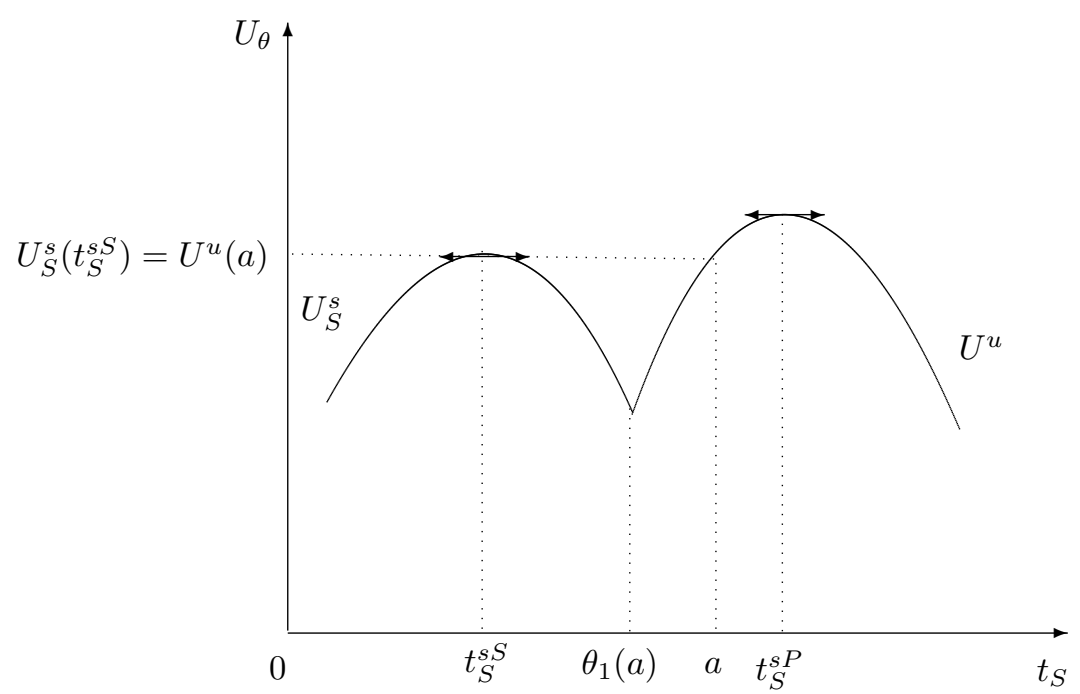

Figure 9: Case (ii): $U_{S}^{s}\left(t_{S}^{s S}\right)=U^{u}(a)$ 


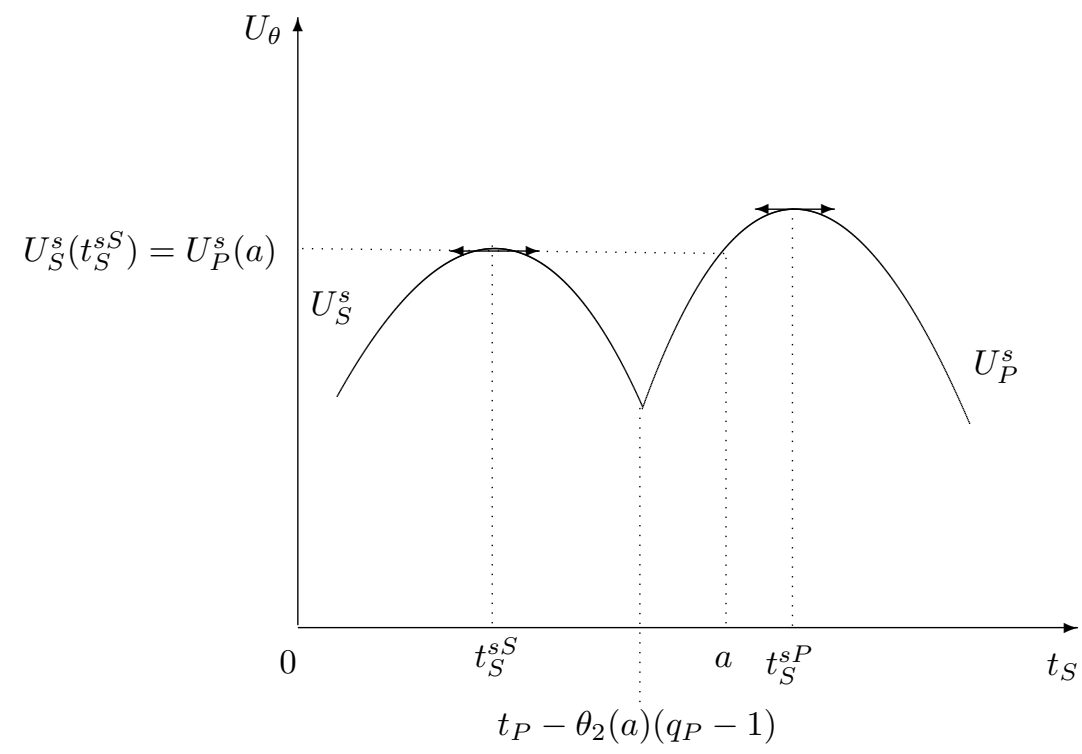

Figure 10: Case $(\mathbf{v}): U_{S}^{s}\left(t_{S}^{s S}\right)=U_{P}^{s}(a)$

Interestingly, $P(a)$ and $R(a)$ are symmetrical w.r.t the $t_{S}$ axis. $P(a)$ reaches its maximum at $t_{S}^{s P}$ and $R(a)$ reaches its minimum at the same value of $t_{S}$. Moreover $P(a)$ and $R(a)$ have the same determinant $\Delta=16 q_{P}^{2}\left(q_{P}-1\right)\left(q_{P}(2 c-\right.$ 1) $\left.+1-2 t_{P}\right)$ which is negative if $t_{P}>\hat{t}_{P}=\frac{1}{2}\left(q_{P}(2 c-1)+1\right)$ and positive otherwise. In the latter case, both polynomials have the same roots $a^{*}$ and $a^{* *}$ such as $a^{*}<a^{* *}$. Here we are only interested in $a^{*}$ as $a^{* *}>t_{S}^{s P}$ whereas $t_{S}^{s S}<a^{*}<t_{S}^{s P}$ if $t_{P}>\tilde{t}_{P}=q_{P}(c-1)+1$ and $t_{S}^{s S}>a^{*}$ otherwise.

Hence, we summarize in the following Figures the three possible cases according to the value of $t_{P}$. 


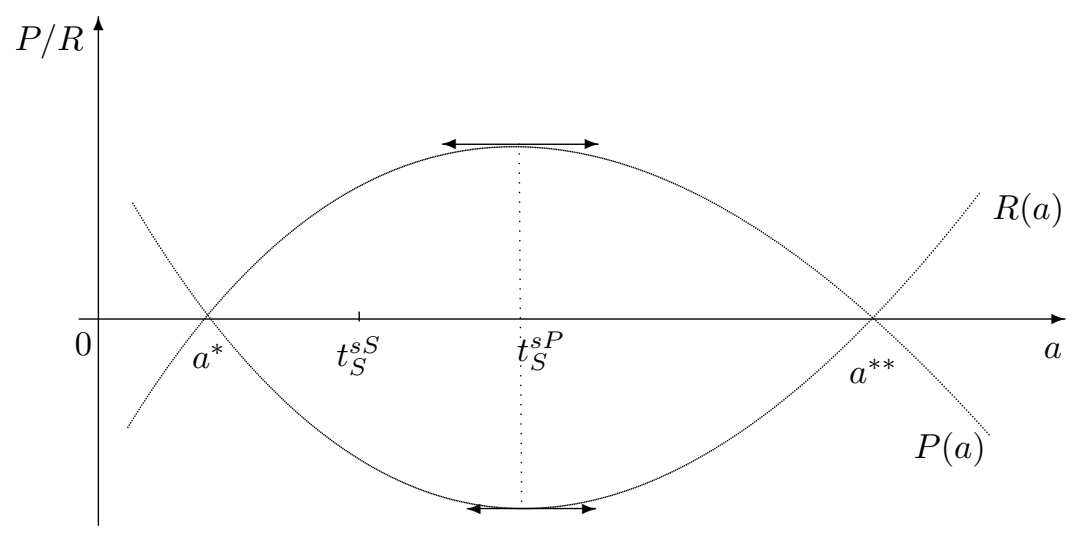

$t_{P}<\tilde{t}_{P}: \Delta>0$ and $a^{*}<t_{S}^{s S}$ 

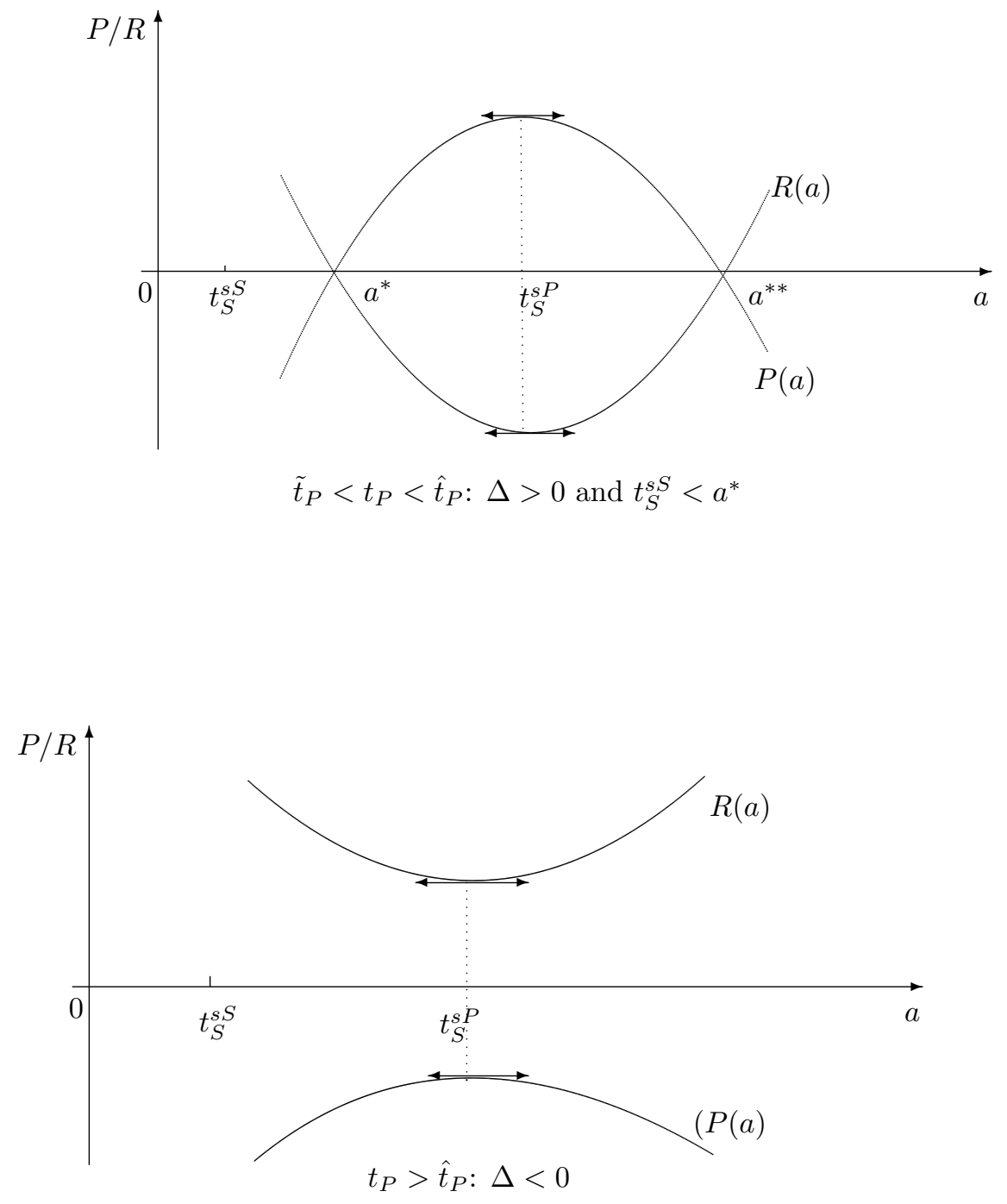

- When $t_{P}<\tilde{t}_{P}, \theta_{1}(a)>\frac{t_{P}}{q_{P}}$ and $\theta_{2}(a)<\frac{t_{P}}{q_{P}}$, which implies that all voters in $[0,1]$ choose $a$. 
- When $\tilde{t}_{P}<t_{P}<\hat{t}_{P}$, for values of $a<a^{*}, \theta_{1}(a)<\frac{t_{P}}{q_{P}}$ and $\theta_{2}(a)>\frac{t_{P}}{q_{P}}$ thus voters in $\left[0, \theta_{1}(a)[\right.$ and those in $\left.] \theta_{2}(a), 1\right]$ choose $a$ whereas those in ]$\theta_{1}(a), \theta_{2}(a)\left[\right.$ choose $t_{S}^{s S}$.

For values of $a>a^{*}, \theta_{1}(a)>\frac{t_{P}}{q_{P}}$ and $\theta_{2}(a)<\frac{t_{P}}{q_{P}}$ thus all voters in $[0,1]$ choose $a$.

- When $t_{P}>\hat{t}_{P}, \theta_{1}(a)<\frac{t_{P}}{q_{P}}$ and $\theta_{2}(a)>\frac{t_{P}}{q_{P}}$ thus voters in $\left[0, \theta_{1}(a)[\right.$ and those in $\left.] \theta_{2}(a), 1\right]$ choose $a$ whereas those in $] \theta_{1}(a), \theta_{2}(a)\left[\right.$ choose $t_{S}^{s S}$.

After comparing $t_{S}^{s S}, t_{S}^{s P}, \frac{t_{P}-t_{S}^{s S}}{q_{P}-1}$ and $\frac{t_{P}-t_{S}^{s P}}{q_{P}-1}$ to $\frac{t_{P}}{q_{P}}$ we finally obtain:

- $t_{P}<\tilde{t}_{P}$ thus $\frac{t_{P}}{q_{P}}<t_{S}^{s S}<t_{S}^{s P}$ and $\frac{t_{P}-t_{S}^{s P}}{q_{P}-1}<\frac{t_{P}-t_{S}^{s S}}{q_{P}-1}<\frac{t_{P}}{q_{P}}$ yielding

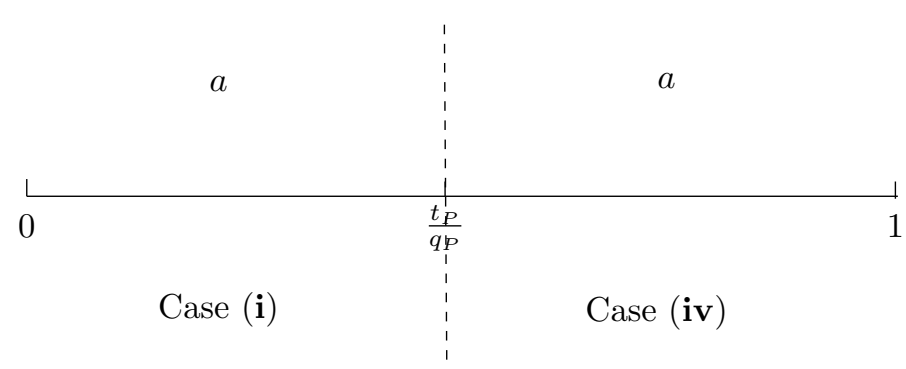

- $\tilde{t}_{P}<t_{P}<\hat{t}_{P}$ thus $t_{S}^{s S}<\frac{t_{P}}{q_{P}}<t_{S}^{s P}$ and $\frac{t_{P}-t_{S}^{s P}}{q_{P}-1}<\frac{t_{P}}{q_{P}}<\frac{t_{P}-t_{S}^{s S}}{q_{P}-1}$, for values of $a<a^{*}$ we obtain

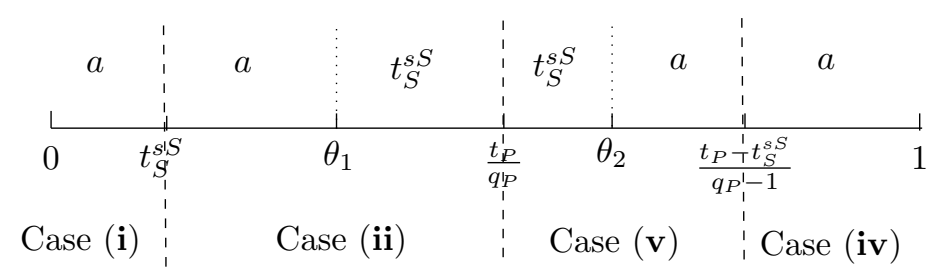

- $\tilde{t}_{P}<t_{P}<\hat{t}_{P}$ thus $t_{S}^{s S}<\frac{t_{P}}{q_{P}}<t_{S}^{s P}$ and $\frac{t_{P}-t_{S}^{s P}}{q_{P}-1}<\frac{t_{P}}{q_{P}}<\frac{t_{P}-t_{S}^{s S}}{q_{P}-1}$, for values of $a>a^{*}$ we obtain

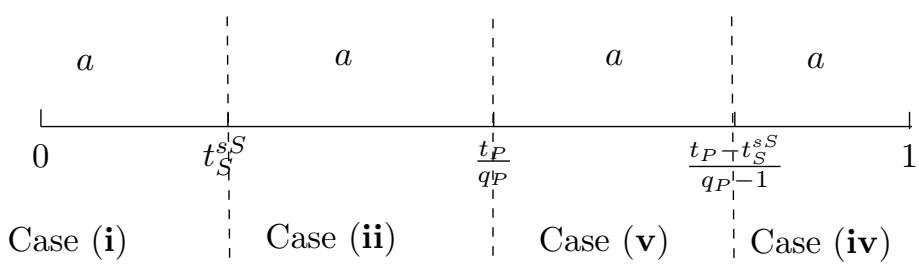


- $\hat{t}_{P}<t_{P}<q_{P} c$ thus $t_{S}^{s S}<\frac{t_{P}}{q_{P}}<t_{S}^{s P}$ and $\frac{t_{P}-t_{S}^{s P}}{q_{P}-1}<\frac{t_{P}}{q_{P}}<\frac{t_{P}-t_{S}^{s S}}{q_{P}-1}$ yielding

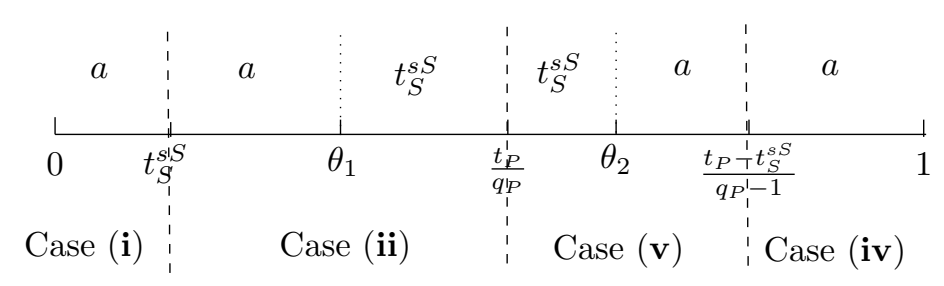

- $t_{P}>q_{P} c$ thus $t_{S}^{s S}<t_{S}^{s P}<\frac{t_{P}}{q_{P}}$ and $\frac{t_{P}}{q_{P}}<\frac{t_{P}-t_{S}^{s P}}{q_{P}-1}<\frac{t_{P}-t_{S}^{s S}}{q_{P}-1}$ yielding

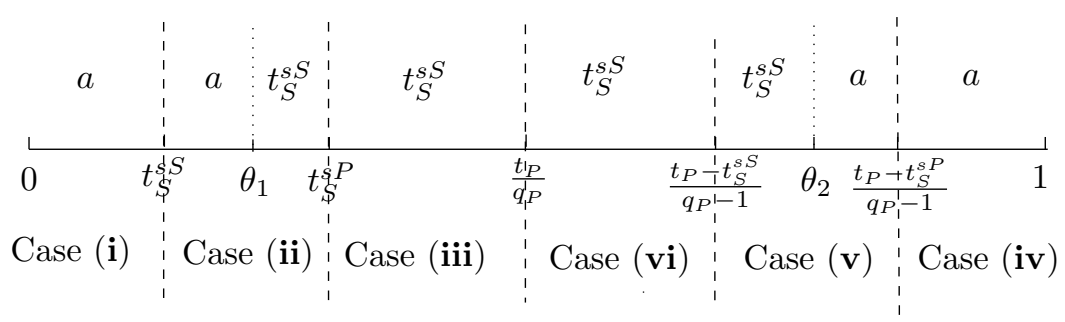

Now we compare $a$ to $t_{S}^{s P}$ in the same way.

- For the cases (i) and (iv) it is clear that all voters choose $t_{S}^{s P}$.

- For the cases (iii) and (vi) it is clear that all voters choose $a$.

- For the cases (ii) and (v) we compare respectively $U^{u}\left(t_{S}^{s P}\right)$ to $U_{S}^{s}(a)$ and $U_{P}^{s}\left(t_{S}^{s P}\right)$ to $U_{S}^{s}(a)$. As depicted in Figures 11 and 12 we denote respectively $\theta_{3}(a)$ and $\theta_{4}(a)$ the values of $\theta$ at which $U^{u}\left(t_{S}^{s P}\right)=U_{S}^{s}(a)$ and $U_{P}^{s}\left(t_{S}^{s P}\right)=$ $U_{S}^{s}(a)$.

$$
\begin{gathered}
\theta_{3}(a)=\frac{\left.\left(4 a(a-c+1)+c^{2}\right) q_{P}^{2}+\left(2 t_{P} c-4 a\left(t_{P}+1\right)\right) q_{P}+t_{P}^{2}\right)}{4 q_{P}\left(q_{P}-1\right)} \\
\theta_{4}(a)=-\frac{\left.\left(4 a(a-c+1)-4 t_{P}+c^{2}\right) q_{P}^{2}+\left(2 t_{P}(c+2)-4 a\left(t_{P}+1\right)\right) q_{P}+t_{P}^{2}\right)}{4 q_{P}\left(q_{P}-1\right)^{2}} .
\end{gathered}
$$

We compare $\theta_{3}(a)$ and $\theta_{4}(a)$ to $\frac{t_{P}}{q_{P}}$,

$$
\begin{aligned}
\theta_{3}(a)-\frac{t_{P}}{q_{P}} & =\frac{\left(4 a(a-c+1)+c^{2}\right) q_{P}^{2}+\left(2 t_{P}(c-2(a+1))-4 a\right) q_{P}+4 t_{P}\left(t_{P}+1\right)}{4 q_{P}\left(q_{P}-1\right)} \\
& =\frac{S(a)}{4 q_{P}\left(q_{P}-1\right)}
\end{aligned}
$$




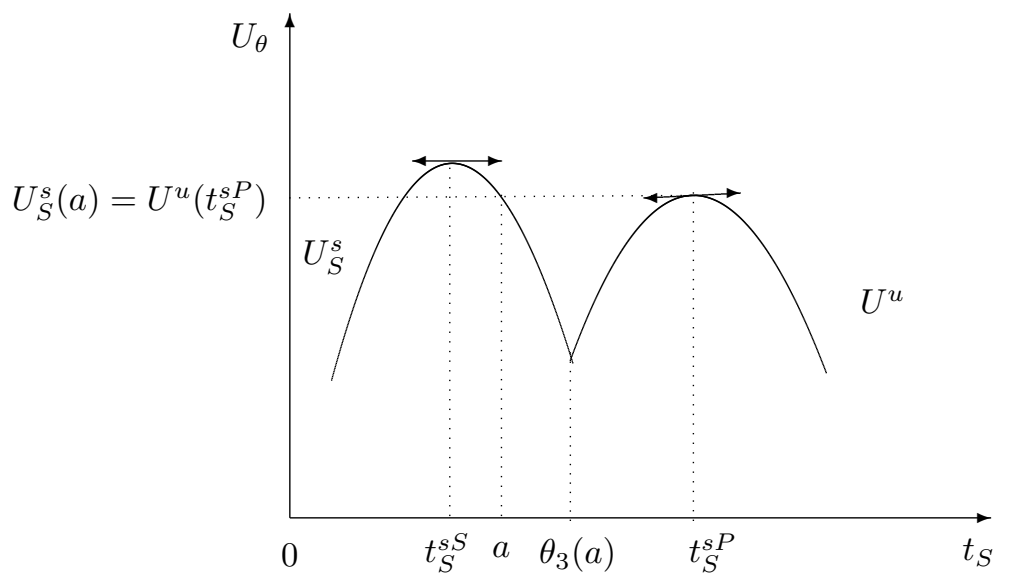

Figure 11: Case (ii): $U_{S}^{s}(a)=U_{P}^{s}\left(t_{S}^{s P}\right)$

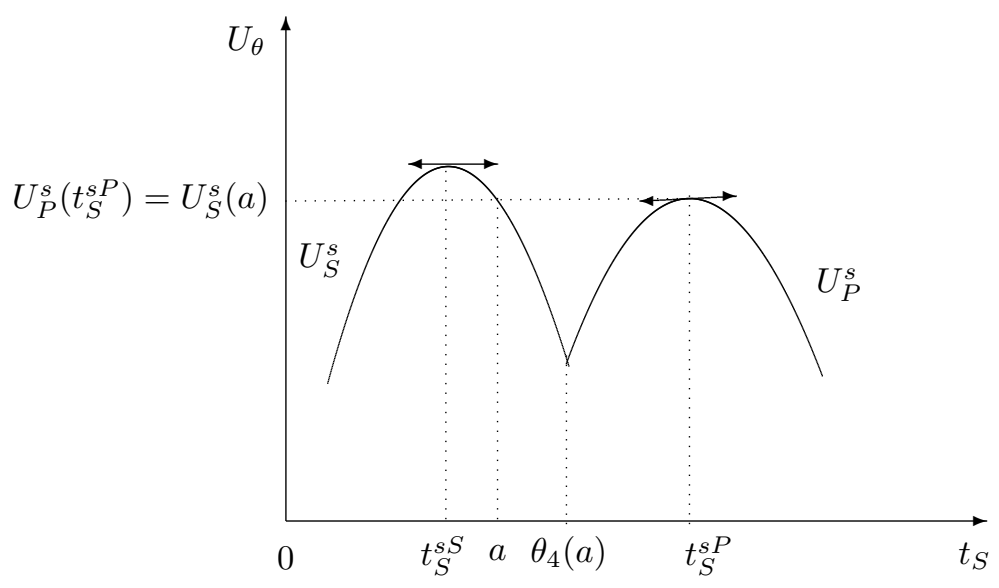

Figure 12: Case $(\mathbf{v}): U_{S}^{s}(a)=U_{P}^{s}\left(t_{S}^{s P}\right)$

and

$$
\begin{aligned}
\theta_{4}(a)-\frac{t_{P}}{q_{P}} & =-\frac{\left(4 a(a-c+1)+c^{2}\right) q_{P}^{2}+\left(2 t_{P}(c-2(a+1))-4 a\right) q_{P}+4 t_{P}\left(t_{P}+1\right)}{4 q_{P}\left(q_{P}-1\right)} \\
& =\frac{M(a)}{4 q_{P}\left(q_{P}-1\right)}
\end{aligned}
$$

$S(a)$ and $M(a)$ are symmetrical w.r.t $t_{S}$ axis. $S(a)$ is convex and reaches its minimum value at $t_{S}^{s S}$ and symmetrically $M(a)$ is concave and reaches its maximum value at $t_{S}^{s S}$. Their common determinant is given by $-16 q_{P}^{2}\left(q_{P}-\right.$ 
1) $\left((2 c-1) q_{P}+1-2 t_{P}\right)$ which is positive if $t_{P}>\hat{t}_{p}$ and negative otherwise. We denote by $a^{+}$and $a^{++}$the common roots (if they exist) such as $a^{+}<a^{++}$. We are only interested in $a^{++}$as $a^{+}<t_{S}^{s S}$ whereas $t_{S}^{s S}<a^{++}<t_{S}^{s P}$ if $\hat{t}_{P}<t_{P}<$ $q_{P} c$ and $a^{++}>t_{S}^{s P}$ if $t_{P}>q_{P} c$.

We summarize in the following figures the possible cases according to $t_{P}$ :
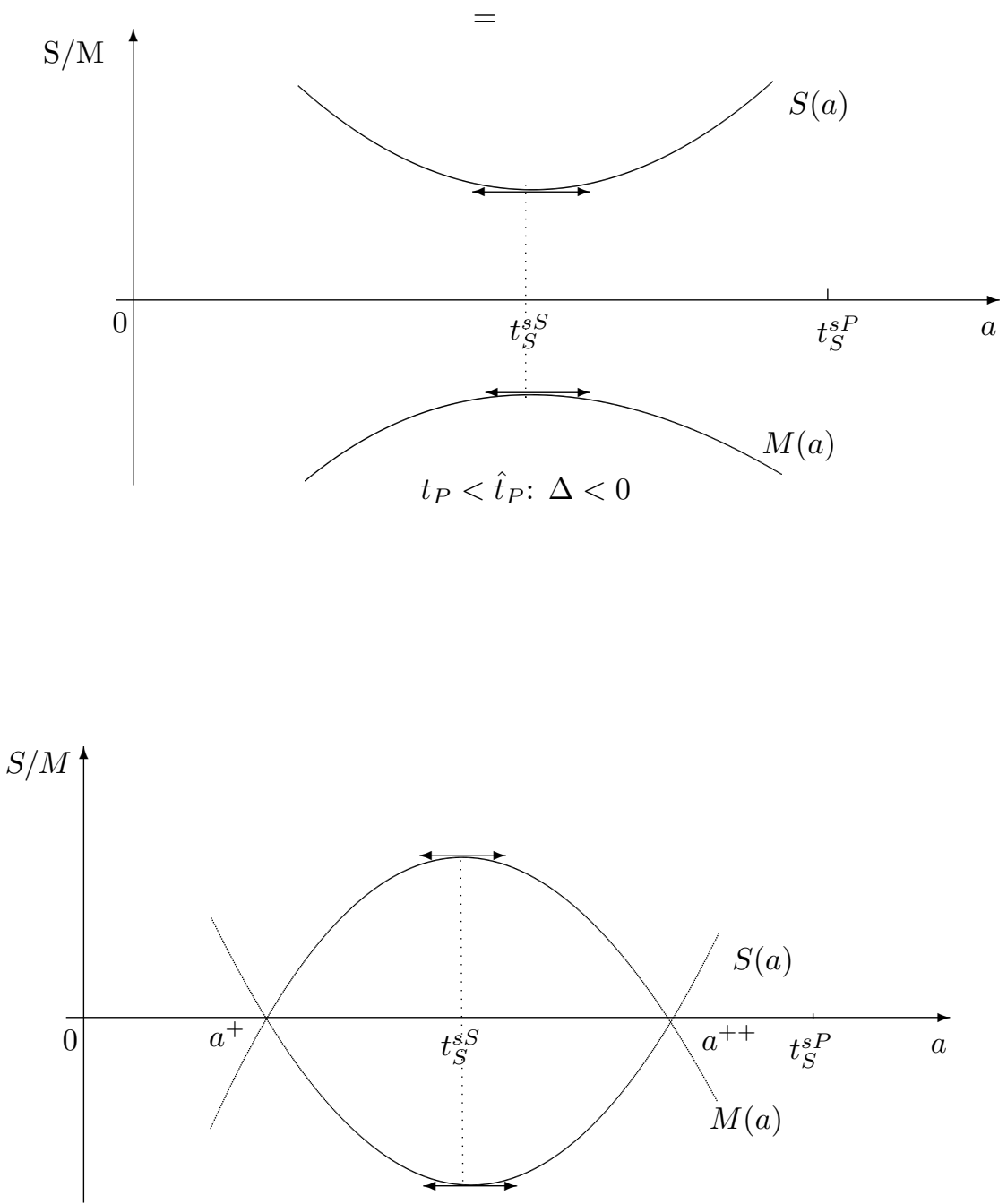

$\hat{t}_{P}<t_{P}<q_{P} c: \Delta>0$ and $a^{++}<t_{S}^{s P}$ 


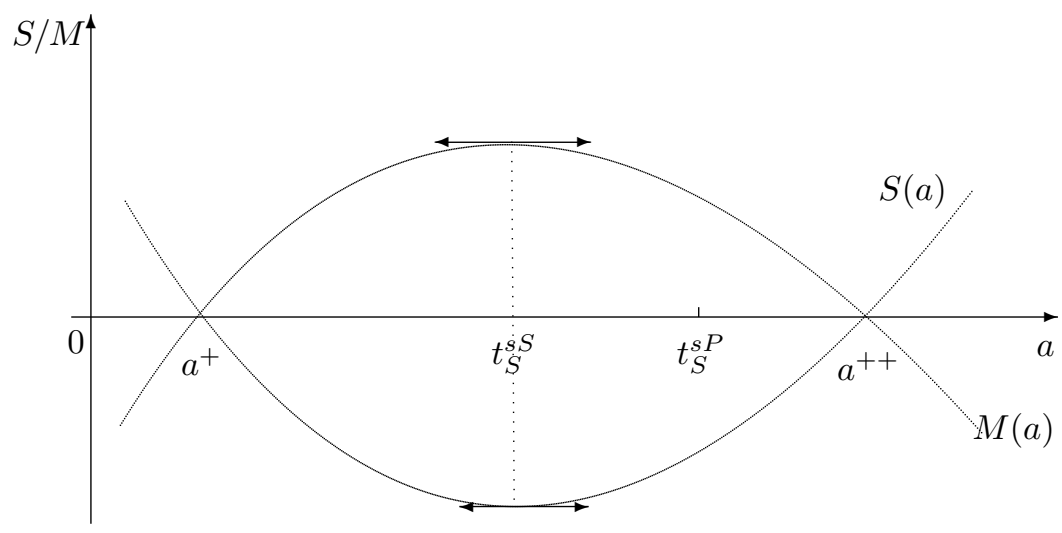

$$
t_{P}>q_{P} c: \Delta>0 \text { and } a^{++}>t_{S}^{s P}
$$

- When $t_{P}<\hat{t}_{P}, \theta_{3}(a)>\frac{t_{P}}{q_{P}}$ and $\theta_{4}(a)<\frac{t_{P}}{q_{P}}$, hence all voters in $[0,1]$ choose $t_{S}^{s P}$.

- When $\hat{t}_{P}<t_{P}<q_{P} c$, for values of $a<a^{++}, \theta_{3}(a)<\frac{t_{P}}{q_{P}}$ and $\theta_{4}(a)>\frac{t_{P}}{q_{P}}$, hence all voters in $\left[0, \theta_{3}(a)[\right.$ and $\left.] \theta_{4}(a), 1\right]$ choose $t_{S}^{s P}$ whereas those in ]$\theta_{3}(a), \theta_{4}(a)[$ vote for $a$.

For values of $a>a^{++} \theta_{3}(a)>\frac{t_{P}}{q_{P}}$ and $\theta_{4}(a)<\frac{t_{P}}{q_{P}}$, hence all voters in $[0,1]$ choose $t_{S}^{s P}$.

- When $t_{P}>q_{P} c, \theta_{3}(a)<\frac{t_{P}}{q_{P}}$ and $\theta_{4}(a)>\frac{t_{P}}{q_{P}}$, hence all voters in $\left[0, \theta_{3}(a)[\right.$ and $\left.] \theta_{4}(a), 1\right]$ choose $t_{S}^{s P}$ whereas those in $] \theta_{3}(a), \theta_{4}(a)[$ vote for $a$.

Comparing $t_{S}^{s S}, t_{S}^{s P}, \frac{t_{P}-t_{S}^{S S}}{q_{P}-1}$ and $\frac{t_{P}-t_{S}^{S P}}{q_{P}-1}$ to $\frac{t_{P}}{q_{P}}$ we finally obtain:

- $t_{P}<\tilde{t}_{P}$ thus $\frac{t_{P}}{q_{P}}<t_{S}^{s S}<t_{S}^{s P}$ and $\frac{t_{P}-t_{S}^{s P}}{q_{P}-1}<\frac{t_{P}-t_{S}^{s S}}{q_{P}-1}<\frac{t_{P}}{q_{P}}$ yielding 


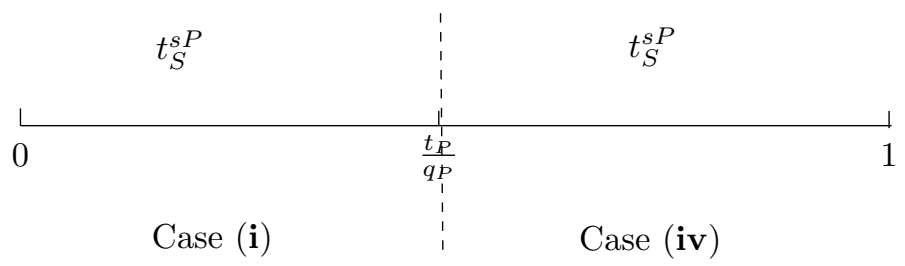

- $\tilde{t}_{P}<t_{P}<\hat{t}_{P}$ thus $t_{S}^{s S}<\frac{t_{P}}{q_{P}}<t_{S}^{s P}$ and $\frac{t_{P}-t_{S}^{s P}}{q_{P}-1}<\frac{t_{P}}{q_{P}}<\frac{t_{P}-t_{S}^{s S}}{q_{P}-1}$, which yields

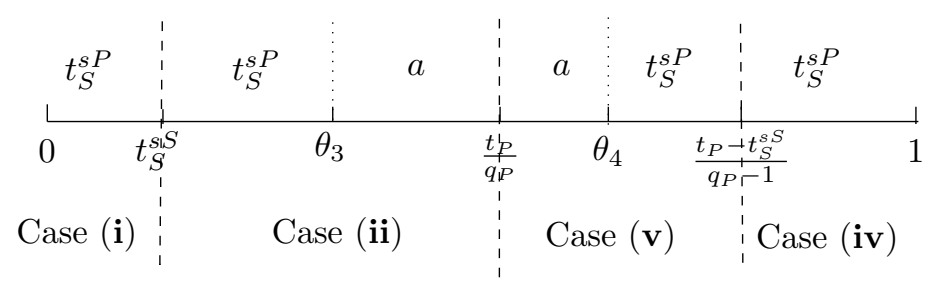

- $\hat{t}_{P}<t_{P}<q_{P} c$ thus $t_{S}^{s S}<\frac{t_{P}}{q_{P}}<t_{S}^{s P}$ and $\frac{t_{P}-t_{S}^{s P}}{q_{P}-1}<\frac{t_{P}}{q_{P}}<\frac{t_{P}-t_{S}^{s S}}{q_{P}-1}$ for values of $a<a^{++}$we obtain

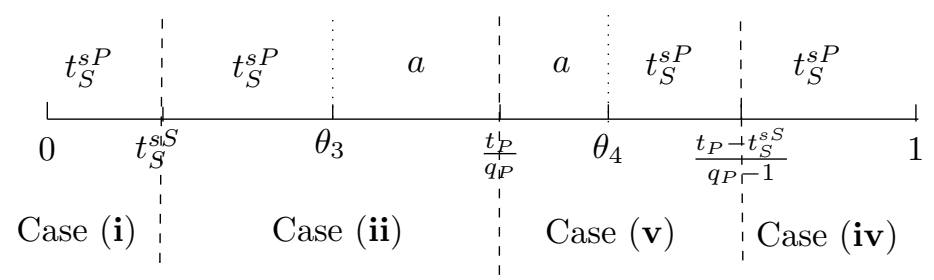

- $\hat{t}_{P}<t_{P}<q_{P} c$ thus $t_{S}^{s S}<\frac{t_{P}}{q_{P}}<t_{S}^{s P}$ and $\frac{t_{P}-t_{S}^{s P}}{q_{P}-1}<\frac{t_{P}}{q_{P}}<\frac{t_{P}-t_{S}^{s S}}{q_{P}-1}$ for values of $a>a^{++}$we obtain

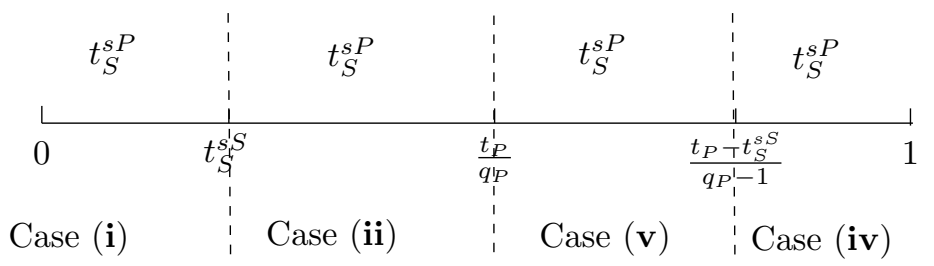

- $t_{P}>q_{P} c$ thus $t_{S}^{s S}<t_{S}^{s P}<\frac{t_{P}}{q_{P}}$ and $\frac{t_{P}}{q_{P}}<\frac{t_{P}-t_{S}^{s P}}{q_{P}-1}<\frac{t_{P}-t_{S}^{s S}}{q_{P}-1}$ yielding 


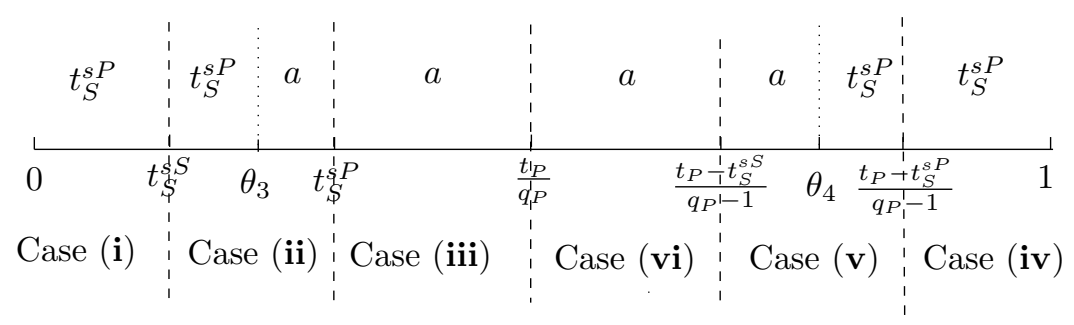

We conclude that $a$ might be a Condorcet winner only when $\hat{t}_{P}<t_{P}<q_{P} c$ for $t_{S}^{s S}<a<a^{++}$and $t_{P}>q_{P} c \quad \forall a \in\left[t_{S}^{s S}, t_{S}^{s P}\right]$. For all other values of $t_{P} a$ is defeated by either $t_{S}^{s S}$ or $t_{S}^{s P}$.

Now we prove that even for these cases $a$ cannot be a Condorcet winner. The idea is to prove that $\theta_{1}+1-\theta_{2}$, i.e. the number of voters for $a$ against $t_{S}^{s S}$, and $\theta_{4}-\theta_{3}$, i.e. the number of voters for $a$ against $t_{S}^{s P}$, are never a majority at the same time, thus $a$ is defeated by either $t_{S}^{s S}$ or $t_{S}^{S P}$.

$$
\begin{aligned}
\theta_{1}-\theta_{2}+\frac{1}{2} & =\frac{\left(4 a(c-a)-c^{2}+2 c+1\right) q_{P}^{2}-\left(2(c+1)+2 t_{P}(c+1-2 a)\right) q_{P}-t_{P}^{2}+2 t_{P}+1}{4\left(q_{P}-1\right)^{2}} \\
& =\frac{L(a)}{4\left(q_{P}-1\right)^{2}} \\
\theta_{4}-\theta_{3}-\frac{1}{2} & =\frac{\left(4 a(c-a-1)-c^{2}-2\right) q_{P}^{2}+\left(4(a+1)\left(t_{P}+1\right)-2 t_{P} c\right) q_{P}-t_{P}^{2}-4 t_{P}-2}{4\left(q_{P}-1\right)^{2}} \\
& =\frac{H(a)}{4\left(q_{P}-1\right)^{2}}
\end{aligned}
$$

On the one hand the polynomial $L$ is concave and reaches its maximum value at $t_{S}^{s P}$, his determinant is given by $\Delta_{L}=\left(q_{P}-1\right)\left(q_{P}(2 c+1)-1-2 t_{P}\right)$ which is positive for values of $t_{P}<\frac{1}{2}\left(q_{P}(2 c+1)-1\right)$ and negative otherwise. On the other hand the polynomial $H$ is concave and reaches its maximum value at $t_{S}^{s S}$, his determinant is given by $\Delta_{H}=-\left(q_{P}-1\right)\left(q_{P}(2 c+1)-1-2 t_{P}\right)$ which is negative for values of $t_{P}<\frac{1}{2}\left(q_{P}(2 c+1)-1\right)$ and positive otherwise.

Hence as depicted below, when $t_{P}<\frac{1}{2}\left(q_{P}(2 c+1)-1\right), \theta_{4}-\theta_{3}<\frac{1}{2}$, i.e. $a$ is defeated by $t_{S}^{s P}$. Otherwise when $t_{P}>\frac{1}{2}\left(q_{P}(2 c+1)-1\right), \theta_{1}+1-\theta_{2}<\frac{1}{2}$, i.e. $a$ is defeated by $t_{S}^{s S}$. 

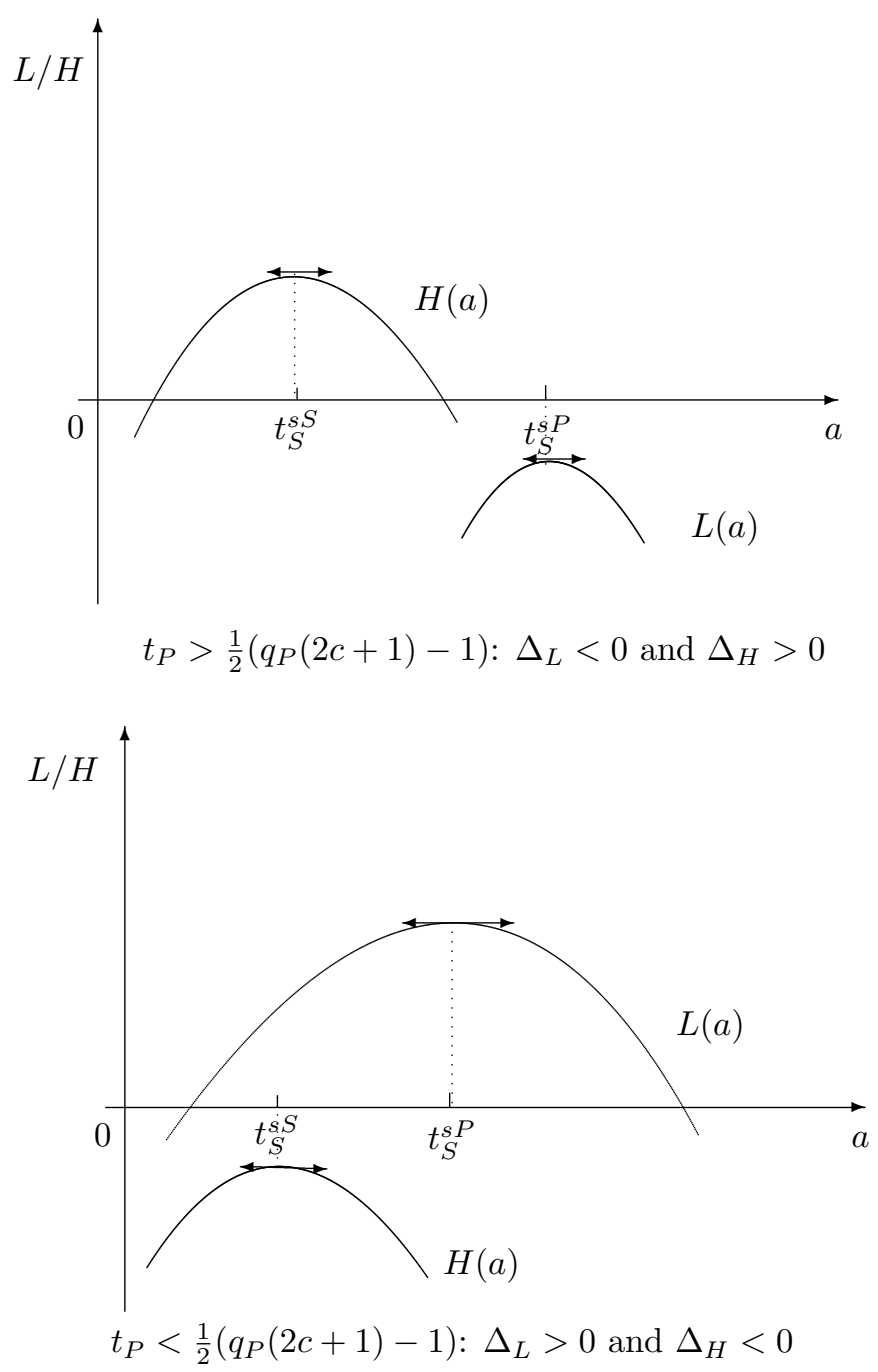

Proof of Lemma 2. As proved in lemma 1 there are only two possible Condorcet winners $t_{S}^{s S}$ and $t_{S}^{s P}$. We determine in what follows the best response function for voters.

As explained previously the utility function is different whether agents are in $\left[0, \frac{t_{p}}{q_{p}}\right]$ or $\left.] \frac{t_{p}}{q_{p}}, 1\right]$. We start by comparing $U_{\theta}\left(t_{S}^{s S}\right)$ and $U_{\theta}\left(t_{S}^{s P}\right)$ for the first segment then for the second to obtain finally the choice of voters in all the interval $[0,1]$. 
- It is clear that for cases (i) and (iv) all voters choose $t_{S}^{s P}$ as the utility function is single-peaked at $t_{S}^{s P}$.

- Similarly for cases (iii) and (vi) all voters choose $t_{S}^{s S}$ as $U_{\theta}$ is single-peaked at $t_{S}^{s S}$.

- For the cases (iii) and (v) we compare respectively $U_{S}^{s}\left(t_{S}^{s S}\right)$ to $U^{u}\left(t_{S}^{s P}\right)$ and $U_{S}^{s}\left(t_{S}^{s S}\right)$ to $U_{P}^{s}\left(t_{S}^{s P}\right)$. As depicted in Figures 13 and 14, we denote respectively by $\theta_{5}$ and $\theta_{6}$ the values of $\theta$ at which $U_{S}^{s}\left(t_{S}^{s S}\right)=U^{u}\left(t_{S}^{s P}\right)$ and $U_{S}^{s}\left(t_{S}^{s S}\right)=U_{P}^{s}\left(t_{S}^{s P}\right)$,

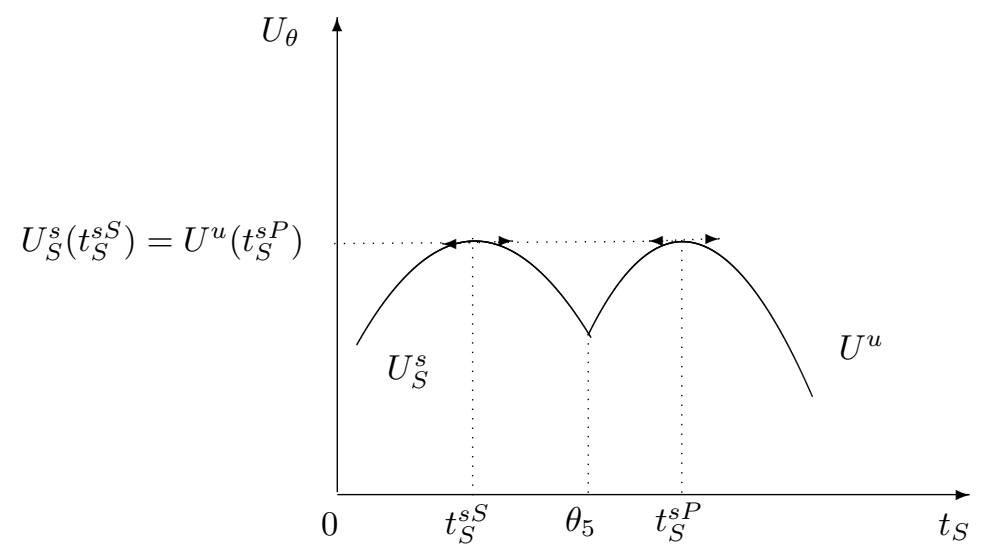

Figure 13: Case (ii): $U_{S}^{s}\left(t_{S}^{s S}\right)=U^{u}\left(t_{S}^{s P}\right)$

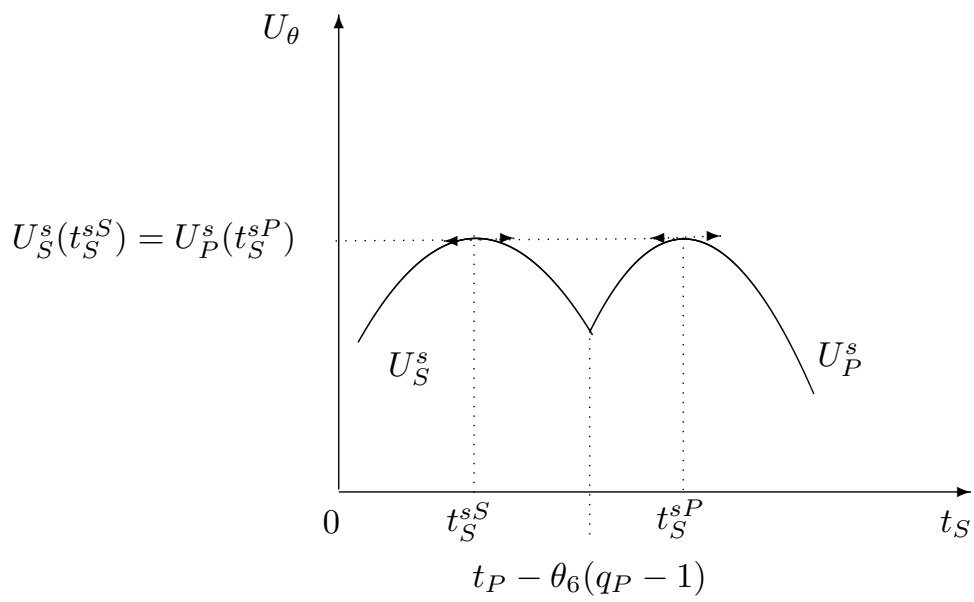

Figure 14: Case (v): $U_{S}^{s}\left(t_{S}^{s S}\right)=U_{P}^{s}\left(t_{S}^{s P}\right)$ 


$$
\begin{gathered}
\theta_{5}=\frac{q_{P}(2 c-1)+1+2 t_{P}}{4 q_{P}}, \\
\theta_{6}=\frac{2 t_{P}\left(2 q_{P}-1\right)-q_{P}(2 c-1)+q_{P}-1}{4 q_{P}\left(q_{P}-1\right)} .
\end{gathered}
$$

Comparing $\theta_{5}$ and $\theta_{6}$ to $\frac{t_{P}}{q_{P}}$ gives:

- iff $t_{P}<\hat{t}_{P}, \theta_{5}>\frac{t_{P}}{q_{P}}$ and $\theta_{6}<\frac{t_{P}}{q_{P}}$ thus all agents choose $t_{S}^{s P}$.

- iff $t_{P}>\hat{t}_{P}, \theta_{5}<\frac{t_{P}}{q_{P}}$ and $\theta_{6}>\frac{t_{P}}{q_{P}}$ thus agents in $\left[0, \theta_{5}[\right.$ and $\left.] \theta_{6}, 1\right]$ vote for $t_{S}^{s P}$ and those in $\left[\theta_{5}, \theta_{6}\right]$ choose $t_{S}^{s S}$.

After comparing $t_{S}^{s S}, t_{S}^{s P}, \frac{t_{P}-t_{S}^{s S}}{q_{P}-1}$ and $\frac{t_{P}-t_{S}^{s P}}{q_{P}-1}$ to $\frac{t_{P}}{q_{P}}$ we finally obtain:

- $t_{P}<\tilde{t}_{P}$ thus $\frac{t_{P}}{q_{P}}<t_{S}^{s S}<t_{S}^{s P}$ and $\frac{t_{P}-t_{S}^{s P}}{q_{P}-1}<\frac{t_{P}-t_{S}^{s S}}{q_{P}-1}<\frac{t_{P}}{q_{P}}$ yielding

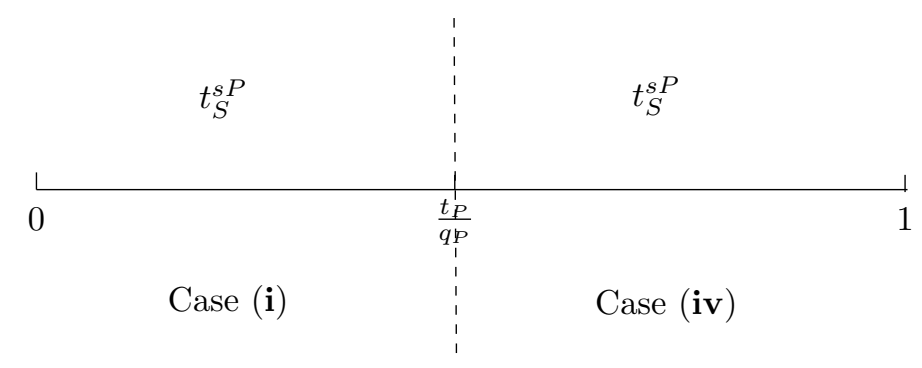

- $\tilde{t}_{P}<t_{P}<\hat{t}_{P}$ thus $t_{S}^{s S}<\frac{t_{P}}{q_{P}}<t_{S}^{s P}$ and $\frac{t_{P}-t_{S}^{s P}}{q_{P}-1}<\frac{t_{P}}{q_{P}}<\frac{t_{P}-t_{S}^{s S}}{q_{P}-1}$, which yields

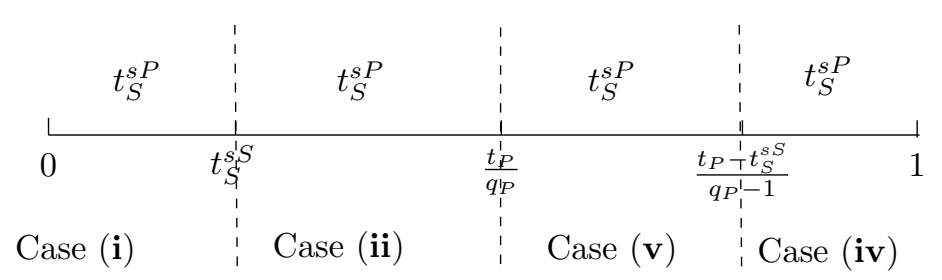

- $\hat{t}_{P}<t_{P}<q_{P} c$ thus $t_{S}^{s S}<\frac{t_{P}}{q_{P}}<t_{S}^{s P}$ and $\frac{t_{P}-t_{S}^{s P}}{q_{P}-1}<\frac{t_{P}}{q_{P}}<\frac{t_{P}-t_{S}^{s S}}{q_{P}-1}$ yielding 


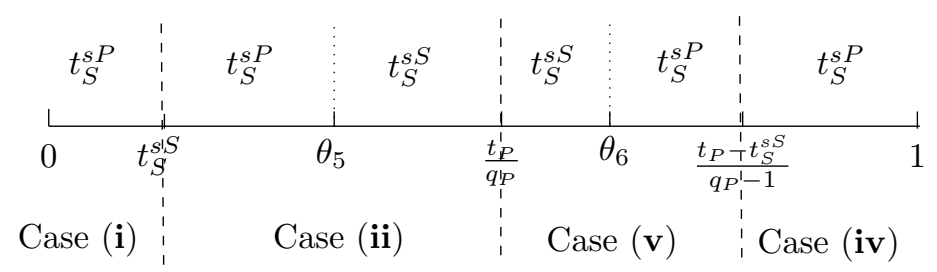

- $t_{P}>q_{P} c$ thus $t_{S}^{s S}<t_{S}^{s P}<\frac{t_{P}}{q_{P}}$ and $\frac{t_{P}}{q_{P}}<\frac{t_{P}-t_{S}^{s P}}{q_{P}-1}<\frac{t_{P}-t_{S}^{s S}}{q_{P}-1}$ yielding

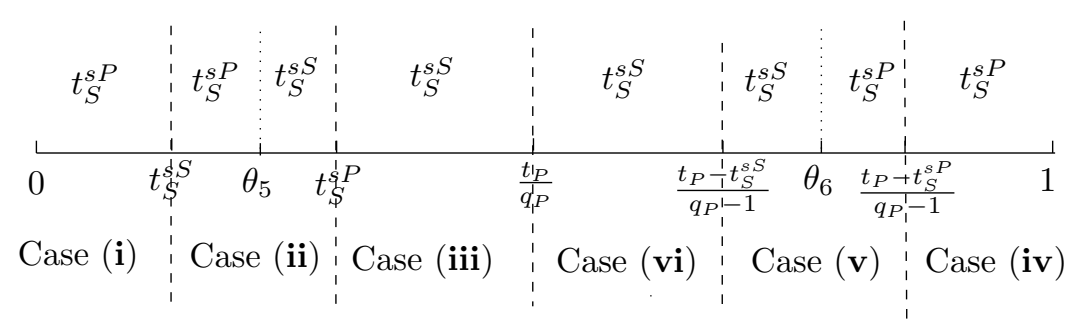

The choice of voters is summarized as follows:

- iff $t_{P}<\hat{t}_{P}$ all voters in $[0,1]$ choose $t_{S}^{s P}$,

- iff $t_{P}>\hat{t}_{P}$ the number of voters who choose $t_{S}^{s P}$ is given by:

$$
V^{u / s P}\left(t_{P}\right)=\theta_{1}+1-\theta_{2}=\frac{-3+(3+2 c) q_{P}-2 t_{P}}{4\left(q_{P}-1\right)} .
$$

$V^{u / s P}$ is a majority when $t_{P}<\frac{1}{2}\left(q_{P}(2 c+1)-1\right)$, thus $t_{S}^{s P}$ is a majority for all values of $t_{P}<\frac{1}{2}\left(q_{P}(2 c+1)-1\right)$ as $\frac{1}{2}\left(q_{P}(2 c+1)-1\right)>\hat{t}_{P}$. Hence the best response function of voters is given by:

$$
t_{S}\left(t_{P}\right)= \begin{cases}t_{S}^{s P}=\frac{q_{P} c+t_{P}}{2 q_{P}}, & \text { iff } t_{P}<\frac{1}{2}\left(q_{P}(2 c+1)-1\right) ; \\ t_{S}^{s S}=\frac{q_{P}(c-1)+t_{P}+1}{2 q_{P}}, & \text { iff } t_{P}>\frac{1}{2}\left(q_{P}(2 c+1)-1\right) .\end{cases}
$$

From (10) and (4) we distinguish three types of equilibria as depicted in Figure 1; two equilibria in pure strategies given by the intersections of $t_{S}^{s P}\left(t_{P}\right)$ and $t_{P 1}$, i.e $t_{S}^{s P}$ is a majority, and $t_{S}^{s S}\left(t_{P}\right)$ and $t_{P 3}$, i.e. $t_{S}^{s S}$ is a majority. The third equilibrium is in mixed strategies where $t_{P 2}$ intersects neither $t_{S}^{s P}\left(t_{P}\right)$ or $t_{S}^{s S}\left(t_{P}\right)$, i.e. there is a tie vote.

Proof of Proposition 1. From (10) and (4), when there is a majority voting for $t_{S}^{s P}$, at equilibrium tuition fees are obtained as,

$$
\left\{\begin{array}{l}
t_{S}^{*}=\frac{\left(q_{P}-1\right)(1+m)+c\left(2 q_{P}+1\right)}{4 q_{P}-1} \\
t_{P}^{*}=\frac{\left.q_{P}\left(2(1+m) q_{P}-1\right)+3 c\right)}{4 q_{P}-1}
\end{array}\right.
$$


which yields the number of voters $V^{u / s P *}=\frac{4 q_{P}(2(c+1)-m)-3}{4\left(4 q_{P}-1\right)} . \quad V^{u / s P *}>\frac{1}{2}$ implies $q_{P}(2 c-m)-\frac{1}{4}>0$. Hence, there is a majority "ends against the middle" only for values of $m<2 c-\frac{1}{4 q_{P}}$, equivalently $q_{P}>\frac{1}{4(2 c-m)}$.

We show that $c \leq \frac{1}{2}$ is sufficient to ensure that both demands are positive, i.e. both universities are open.

- We first prove that for values of $c \leq \frac{1}{2}, D_{P}^{*} \geq 0$,

$$
D_{P}^{*}=\left(1-\frac{t_{P}^{*}-t_{S}^{*}}{q_{P}-1}\right)=\frac{2 q_{P}-c-m\left(2 q_{P}-1\right)}{4 q_{P}-1} .
$$

It is easy to see that $D_{P}^{*} \geq 0$ iff $m \leq \frac{2 q_{P}-c}{2 q_{P}-1}$. Otherwise

$$
\frac{2 q_{P}-c}{2 q_{P}-1}-2 c=\frac{2(1-2 c) q_{P}+c}{2 q_{P}-1},
$$

$2 c-\frac{2 \hat{q}_{P}-c}{2 \hat{q}_{P}-1}=0$ when $\hat{q}_{P}=\frac{c}{2(2 c-1)}$ which is negative when $c \leq \frac{1}{2}$, thus for all values of $q_{P}>\frac{1}{4(2 c-m)}, \frac{2 q_{P}-c}{2 q_{P}-1}>2 c$ which implies $2 q_{P}(1-2 c)+c \geq 0$. QED.

- Then we prove that when $c \leq \frac{1}{2}, D_{S}^{*} \geq 0$,

$$
D_{S}^{*}=\frac{t_{P}^{*}-t_{S}^{*}}{q_{P}-1}-t_{S}^{*}=\frac{q_{P}(m-2 c+1)}{4 q_{P}-1} .
$$

It is easy to see that $D_{s}^{*} \geq 0$ iff $m \geq 2 c-1$. This condition holds always true since $m>2 c-\frac{1}{4 q_{P}}>2 c-1$.

Proof of Proposition 2. From (10) and (4) when there is a majority voting for $t_{S}^{s S}$, at equilibrium tuition fees are obtained as,

$$
\left\{\begin{aligned}
t_{S}^{*} & =\frac{\left(q_{P}-1\right)(m-1)+c\left(2 q_{P}+1\right)}{4 q_{P}-1}, \\
t_{P}^{*} & =\frac{1+q_{P}\left(2(1+m)\left(q_{P}-1\right)+3 c-1\right)}{4 q_{P}-1},
\end{aligned}\right.
$$

which leads to the number of voters $V^{u / s P *}=\frac{-1+4 q_{P}(2(1+c)-m)}{4\left(4 q_{P}-1\right)} . V^{u / s P *}<\frac{1}{2}$ implies $q_{P}(2 c-m)+\frac{1}{4}<0$. Hence there is a majority "middle against the ends" for values of $m>2 c+\frac{1}{4 q_{P}}$, equivalently $q_{P}>\frac{1}{4(m-2 c)}$.

We determine conditions under which at equilibrium both universities are open.

- We first prove that $D_{S}$ is always positive,

$$
D_{S}^{*}=\frac{t_{P}^{*}-t_{S}^{*}}{q_{P}-1}-t_{S}^{*}=\frac{m q_{P}+3 q_{P}-2 c q_{P}-1}{4 q_{P}-1} .
$$

$D_{S} \geq 0$ iff $m>-3+2 c+\frac{1}{q_{P}}$ which is always true. 
- Then we prove that for low enough values of $c$, there always exists a nonvoid interval of values of $m,\left[2 c+\frac{1}{4 q_{P}}, 1-\frac{c}{2 q_{P}-1}\right]$, for which the private university is open.

$$
D_{P}^{*}=\left(1-\frac{t_{P}^{*}-t_{S}^{*}}{q_{P}-1}\right)=-\frac{m\left(2 q_{P}-1\right)+c+1-2 q_{P}}{4 q_{P}-1},
$$

$D_{P}^{*} \geq 0$ iff $m \leq 1-\frac{c}{2 q_{P}-1}$. We check under what condition $1-\frac{c}{2 q_{P}-1}>$ $2 c+\frac{1}{4 q_{P}}$ : this inequality holds whenever $c<\frac{2 q_{P}-1}{4 q_{P}}$. It is easy to see that this inequality holds always true if $c<\frac{1}{3}$.

Proof of Proposition 3. There is a tie vote between the extremes and the middle class when $V^{u / s P}=\frac{1}{2}$ yielding $t_{P} c r i t=\frac{1}{2}\left((1+2 c) q_{P}-1\right)$. Hence at equilibrium,

$$
\frac{1}{2}\left(c+(m+1)\left(q_{P}-1\right)+\lambda t_{S}^{s P}+(1-\lambda) t_{S}^{s S}\right)=t_{P}^{c r i t}
$$

which gives $\lambda^{*}=\frac{1}{2}\left(1+4 q_{P}(2 c-m)\right)$. There is equilibrium only if $0<\lambda^{*}<1$ which means, only for values of $2 c-\frac{1}{4 q_{P}}<m<2 c+\frac{1}{4 q_{P}}$.

We substitute the value of $t_{P}^{c r i t}$ respectively in $t_{S}^{s P}$ and $t_{S}^{s S}$ given in (10) to obtain the equilibrium values of $t_{S}^{*}$ respectively with probability $\lambda^{*}$ and $1-\lambda^{*}$. 